\title{
In Silico Drug Repurposing for coronavirus (COVID-19): Screening known HCV drugs against the SARS-CoV-2 Spike protein bound to angiotensin converting enzyme 2 (ACE2) (6M0J)
}

\author{
K. G. Kalamatianos* \\ Analytical Chemistry and Toxicology Laboratory, I.Y.A., Athens, Greece, 116-36
}

ABSTRACT: In this study FDA approved HCV antiviral drugs and their structural analogues - several of them in clinical trials - were tested for their inhibitory properties towards the SARS-CoV-2 Spike protein bound to angiotensin converting enzyme 2 (ACE2) (6M0J) using a virtual screening approach and computational chemistry methods. The most stable structures and the corresponding binding affinities of thirteen such antiviral compounds were obtained. Frontier molecular orbital theory, global reactivity descriptors, molecular docking calculations and electrostatic potential (ESP) analysis were used to hypothesize the bioactivity of these drugs against $6 \mathrm{MOJ}$. It is found that increased affinity for the protein is shown by inhibitors with large compound volume, relatively higher electrophilicity index, aromatic rings and heteroatoms that participate in hydrogen bonding. Among the drugs tested, four compounds $\underline{\mathbf{1 0}} \underline{\mathbf{1 3}}$ showed excellent results - binding affinities -11.2 to $11.5 \mathrm{kcal} . \mathrm{mol}^{-1}$. These four top scoring compounds may act as lead compounds for further experimental validation, clinical trials and even for the development of more potent antiviral agents against the SARS-CoV-2.

\section{INTRODUCTION}

In December 2019 the first cases of infection from a novel coronavirus were reported. Later the causal organism was reported as a newly mutated strain of SARS Coronavirus and termed SARS-CoV-2. This new coronavirus was implicated in an outbreak of a severe pneumonia like illness COVID-19 ${ }^{1-2}$ and has led to a worldwide pandemic with more than $185,000,000$ cases and 4000000 deaths reported so far. ${ }^{3-8}$

In the past eight months, several pharmaceutical companies have announced hugely successful trials of their Covid-19 vaccines. ${ }^{9}$ Even though these vaccines are promising there is no guarantee that they will cure all those vaccinated and as a consequence there is need for other treatments. Therefore the development of antiviral agents is an urgent priority even though it usually takes many years for new drugs to be discovered, clinically tested and approved. A good strategy would be trying to find already approved drugs that have some efficacy against similar type of viruses. ${ }^{10}$ Then test the efficacy of these drugs against SARS-CoV-2 using computational chemistry methods and molecular docking. ${ }^{11-23}$ The most effective of these drugs can then be clinically tested and approved.

Researchers are attempting to repurpose a wide variety of existing medications for COVID-19, including HCV, HIV, and influenza drugs. Although not closely related, hepatitis $\mathrm{C}$ virus (HCV) and the new coronavirus SARS_CoV-2 are both single-stranded RNA viruses. This has led some scientists to suggest that the same antiviral drugs might work against both. Recently, sofosbuvir and daclatasvir, two antiviral drugs used to treat hepatitis C, were associated with faster recovery, shorter hospitalization and improve survival among people with moderate or severe COVID-19. ${ }^{24}$ If larger studies confirm these findings, generic versions of sofosbuvir and daclatasvir could potentially be an affordable and widely accessible treatment for the new coronavirus.

In a previous study FDA approved antiviral drugs and lopinavir analogues in clinical trials were tested for their inhibitory properties towards the SARS-CoV-2 Spike protein bound to angiotensin converting enzyme 2 (ACE2) (6M0J) using a virtual screening approach and computational chemistry methods. ${ }^{25}$ Among them four compounds showed excellent results - binding interactions -9.0 to $-9.3 \mathrm{kcal}^{\mathrm{mol}}{ }^{-1}$ - for use against the newly emerged strain of coronavirus.

In the present work, approved HCV drugs and their structural analogues in clinical trials are tested for their inhibition towards the COVID-19 protein (6M0J) using in silico methods. The present work has the following objectives: i) To obtain the ground state optimized structures of selected HCV drugs and their analogues (Tables 
1-2) at a semiempirical level (PM3) $)^{26-29}$ and subsequently calculate global reactivity descriptors - chemical potential $(\mu)$, electrophilicity index $(\omega)$ - to identify differences in reactivity. ii) To calculate the energy gap between the highest occupied and the lowest unoccupied molecular orbital (HOMO-LUMO energy gap) of these drugs at the ground state since small energy gaps are associated with higher chemical reactivity and low kinetic stability. ${ }^{30-33}$ iii) To investigate the interaction of the ground state optimized structure of the above approved drugs and their analogues (Table 2) with the SARSCoV-2 Spike protein $(6 \mathrm{MOJ})^{34}$ using computational chemistry methods and molecular docking. iv) To determine the binding affinities of these drugs (ligands) with the SARS-CoV-2 Spike protein (6M0J).

It is known that the virus enters the host cell by binding of the viral spike glycoprotein to the host receptor, angiotensin converting enzyme 2 (ACE2) $)^{35}$ therefore (6M0J) seems to be a biologically meaningful receptor.

\section{COMPUTATIONAL METHODS}

The semiempirical calculations were carried out using the Arguslab software. ${ }^{36} \mathrm{Ab}$ initio molecular orbital calculations were carried out using the ORCA 4.1 quantum chemistry program package ${ }^{37}$ The most stable optimized geometries and frequency calculations of the compounds studied were obtained from the PM3 method at the semiempirical level and from B97-3c/def2$\mathrm{mTZVP}^{38}$ methods and basis set at the ab initio level.

The recent resolved three-dimensional crystal structure of SARS-CoV-2 Spike protein bound to angiotensin converting enzyme 2 (ACE2) (PDB ID: 6M0J) ${ }^{34}$ was retrieved from the Protein Data Bank with a resolution of $2.45 \AA$. Approved drugs and their analogues were downloaded from PubChem. The most stable optimized geometries were obtained as described above and were subjected to molecular docking simulation against the SARS-CoV-2 Spike protein (PDB ID: 6M0J) using the Autodock 4.2 / Autodock Vina ${ }^{39}$ and Autodock ADFR softwares. The binding dissociation constant $\mathrm{k}_{\mathrm{d}}$ between protein and ligand was calculated using $\mathrm{KDEEP}^{40} \mathrm{It}$ is well known that in computer aided drug studies, binding affinity and mode(s) of ligand with target protein can be predicted by molecular docking simulation. ${ }^{41-42}$ In this analysis, flexible-ligand:rigid-receptor docking was performed and accurate docking conditions were selected. All hetero atoms and water molecules were eliminated before docking. The grid box mapping parameters for AutoDock 4.2/Autodock Vina were chosen as follows: Box dimension $(\AA) \mathrm{x}=64 \mathrm{y}=66 \mathrm{z}=72$ and Center $(\AA)$ $\mathrm{x}=-23.088 \mathrm{y}=18.676 \mathrm{z}=-27.106$ along $\mathrm{x}, \mathrm{y}$ and $\mathrm{z}$ directions respectively. Electrostatic potentials on molecular/vdW surfaces were computed using the Multi- functional Wavefunction Analyzer Multiwfn. ${ }^{43}$ Pymol was used to depict protein-ligand interactions. ${ }^{44}$

\section{RESULTS AND DISCUSSION}

The HCV drugs studied in this work are listed in Table 1. Computed binding affinities of these compounds using the procedures described above are collected in Table 2 . The binding affinity values (kcal.mol ${ }^{-1}$ ) computed by AutoDock 4.2/Autodock Vina are averages of ten independent trials. The Autodock ADFR values $\left(\mathrm{kcal}_{\mathrm{mol}} \mathrm{m}^{-1}\right)$ are averages of the best binding affinity values of each ligand with the protein obtained in the five highest scoring pockets. A plot of the Vina and ADFR binding values is shown in Graph A1 (Appendix A). The former values were used throughout this study. The binding dissociation constants $\mathrm{k}_{\mathrm{d}}$ were singly determined. Global reactivity descriptors of the tabulated compounds - hardness (n), softness (s), chemical potential $(\mu)-$ were calculated using the PM3 version of SCF MO and the Arguslab software. ${ }^{36}$ It may be pointed out that in SAR studies the semiempirical SCF methods are more reliable than ab initio methods. ${ }^{45}$ The HOMO and LUMO energy values were obtained for all molecules and then the global reactivity descriptors were calculated from these values considering Koopman's theorem according to the following equations: ${ }^{46-47}$

$$
\begin{gathered}
\mathbf{n} \approx\left(\mathrm{E}_{\text {LUMO }}-\mathrm{E}_{\text {HOMO }}\right) / 2 \\
\mathrm{~s}=1 / \mathrm{n} \\
\boldsymbol{\mu} \approx\left(\mathrm{E}_{\mathrm{LUMO}}+\mathrm{E}_{\mathrm{HOMO}}\right) / 2 \\
\omega=\mu^{2} / 2 \mathrm{n}
\end{gathered}
$$

The results obtained show that best binding energies $(<-10.6 \mathrm{kcal} / \mathrm{mol})$ are observed in most cases for drugs that exhibit both relatively higher electrophilicity indices $\omega$ (electrophilicity index $\omega>0.11$ ) and chemical potential $\mu(\mu>7.6)$ (Table 2). The electrophilicity index $\omega$ encompasses the tendency of an electrophile to acquire an extra amount of electron density. The chemical potential $\mu$ is associated with the feasibility of a system to exchange electron density with the environment.

Assuming that the HCV drugs of Table 2 can be divided into two groups with respect to binding affinities (strong inhibitors $\leq-10.6 \mathrm{kcal}^{\mathrm{mol}}{ }^{-1}$, weak inhibitors > $10.6 \mathrm{kcal} . \mathrm{mol}^{-1}$ a logisitic regression test was performed with covariates $\omega$ (electrophilicity index) and $\mu$ (chemical potential) using SPSS. ${ }^{48}$ The Likehood Ratio tests (Fig. 1) check the contribution of each variable and reveal that $\omega$ is significant (sig. < 0.05). Higher $\omega$ values characterize the strong inhibitor group (binding affinities 
$<-10.6$ kcal.mol $\left.{ }^{-1}\right)$. Elbasvir and paritaprevir analogues 10, 11-13 (Table 1 and 2) fall at the high end of the strong inhibitor category. Elbasvir $\underline{\mathbf{8}}$ and its analogue $\underline{\mathbf{9}}$, paritaprevir analogue $\underline{\mathbf{6}}$ and setrobuvir analogue $\underline{\mathbf{7}}$ fall at the low end of this category. Compounds $\underline{\mathbf{1}}-\underline{\mathbf{5}}$ belong to the weak inhibitor group. The higher binding affinity observed for $\underline{\mathbf{6}}$ - $\underline{\mathbf{1 3}}$ can be attributed mainly to noncovalent interactions. The formed ligand (drug in Table 2) receptor (6M0J) complexes reveal that Pi-alkyl, Pi-Pi

\begin{tabular}{|c|c|c|c|c|c|c|}
\hline \multicolumn{7}{|c|}{ Likelihood Ratio Tests } \\
\hline \multirow[b]{2}{*}{ Effect } & \multicolumn{3}{|c|}{ Model Fitting Criteria } & \multicolumn{3}{|c|}{ Likelihood Ratio Tests } \\
\hline & $\begin{array}{c}\text { AlC of } \\
\text { Reduced } \\
\text { Model }\end{array}$ & $\begin{array}{c}\text { BIC of } \\
\text { Reduced } \\
\text { Model }\end{array}$ & $\begin{array}{l}-2 \log \\
\text { Likelihood of } \\
\text { Reduced } \\
\text { Model }\end{array}$ & Chi-Square & df & Sig. \\
\hline Intercept & 15.329 & 16.459 & 11.329 & .128 & 1 & .721 \\
\hline ELECTR_IND & 19.195 & 20.325 & 15.195 & 3.993 & 1 & .046 \\
\hline CHEM_POT & 16.962 & 18.092 & 12.962 & 1.760 & 1 & .185 \\
\hline
\end{tabular}

Figure 1. Logistic regression Likehood Ratio Tests to check the contribution of the covariates electrophilicity index $\omega$ and chemical potential $\mu$ to the observed binding affinity of the molecules in Table 2 . The electrophilicity index $\omega$ variable (ELECTR_IND) is significant (sig. $<0.05$ ).

stacking, conventional hydrogen bonding and halogen bonds are able to increase the binding affinity and explain the differences in binding energies (Table A1, Appendix A). It has been reported that particularly hydrogen bonds $<2.3 \AA$ are able to increase the binding affinity considerably and that halogen bonds have almost similar importance as hydrogen bonds in chemical and biological systems. ${ }^{49-50}$ Among all sort of interactions such as $\mathrm{CH} / \mathrm{O}, \mathrm{CH} / \mathrm{N}, \mathrm{OH} / \pi$ and $\mathrm{NH} / \pi$, the $\mathrm{CH} / \pi$ is the most prominent interaction found between drugsproteins.

Docking interactions of paritaprevir analogues $\underline{\mathbf{1 2}}$ and $\underline{\mathbf{1 3}}$ (Tables 1, 2 and A1) with 6M0J are shown in Figs. 2 and 3 respectively. Several Pi-Pi stacked, Pi-alkyl interactions and at least one hydrogen bond $<2.3 \AA$ are observed. Three Pi-Pi stacked interactions are observed between the fluorine substituted phenanthridine ring of $\underline{12}$ and PHE390 and four Pi-alkyl interactions with ARG393, PHE40, TRP349 and HIS378. Four hydrogen bonds are formed with the protein. The hydrogen bond with ARG393 is at a distance of $2.25 \AA$. The phenanthridine and pyrazine rings of $\underline{\mathbf{1 3}}$ interact by forming a total of four Pi-Pi stacked interactions with PHE390 and TRP349 respectively. Hydrogen bonds are observed between the oxygen atoms attached to the sulfur atom and ARG514 and the pyrazine nitrogens and SER47. The hydrogen bond with ARG514 is at a distance of $2.02 \AA$ providing increased binding affinity. A Pi-Alkyl interaction is observed between the phenanthridine pi-orbitals and ARG393 (Fig. 3, Table A1). Compounds at the low end of the strong inhibitor category show hydrogen bonding - including hydrogen bonds $<2.3 \AA$ - alkyl and $\mathrm{Pi}$ alkyl bonding but with the exception of $\underline{\mathbf{Z}}$ and elbasvir $\underline{8}$ lack Pi-Pi stacked interactions (Table A1). Elbasvir shows seven conventional hydrogen bond interactions



Figure 2. Docking interactions of compound $\underline{12}$ (Tables $1 \& 2$ ) with $6 \mathrm{MOJ}$ (expanded version in Appendix A).

with 6M0J while three of them with ARG273, HIS345 and HIS505 are $<2.3 \AA$. A total of six Carbon-Hydrogen bond interactions are observed with ALA348, PRO346, GLU375, ASP382, TYR385, PHE390. A Pi-Pi stacked

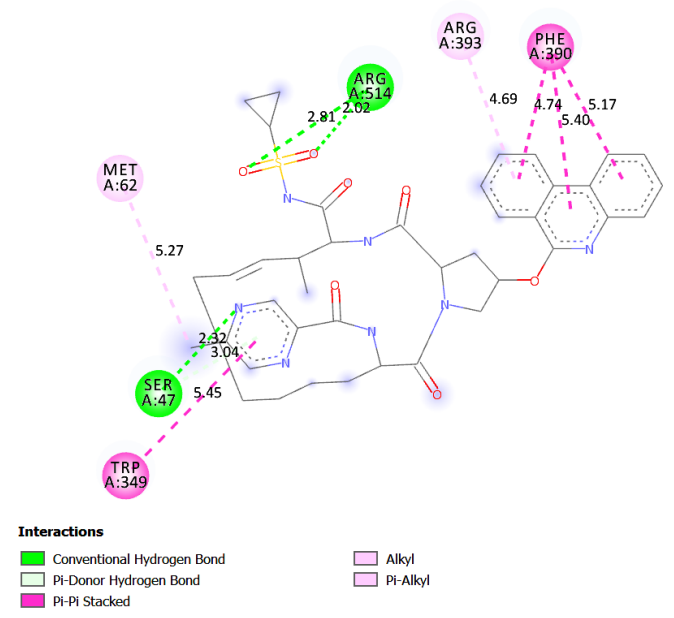

Figure 3. Docking interactions of compound 13 (Tables 1 \& 2) with 6M0J (expanded version in Appendix A).

bonding interaction is formed between the p orbitals of the imidazole ring of $\underline{\mathbf{8}}$ and the p orbitals of HIS345. PiPi-T-shaped interactions are observed between the fused aromatic and 2-pyrroline rings of $\underline{\mathbf{8}}$ and HIS378, TRP349 and HIS401 of the protein. Pi-Alkyl interactions are formed between the 2-pyrroline 




1

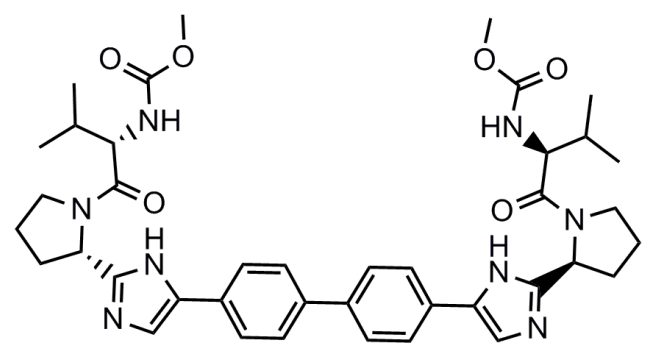

$\underline{2}$

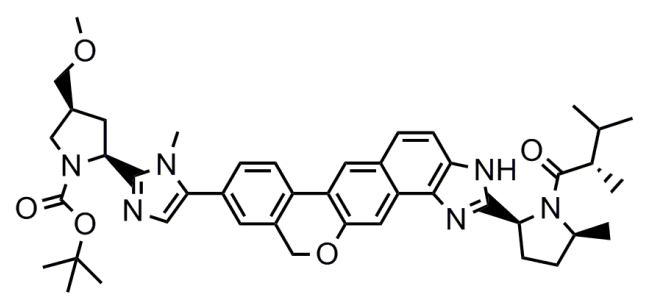

$\underline{3}$

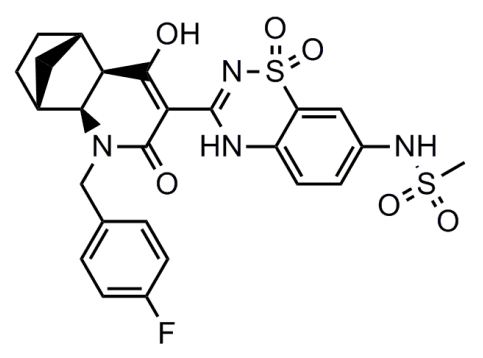

4
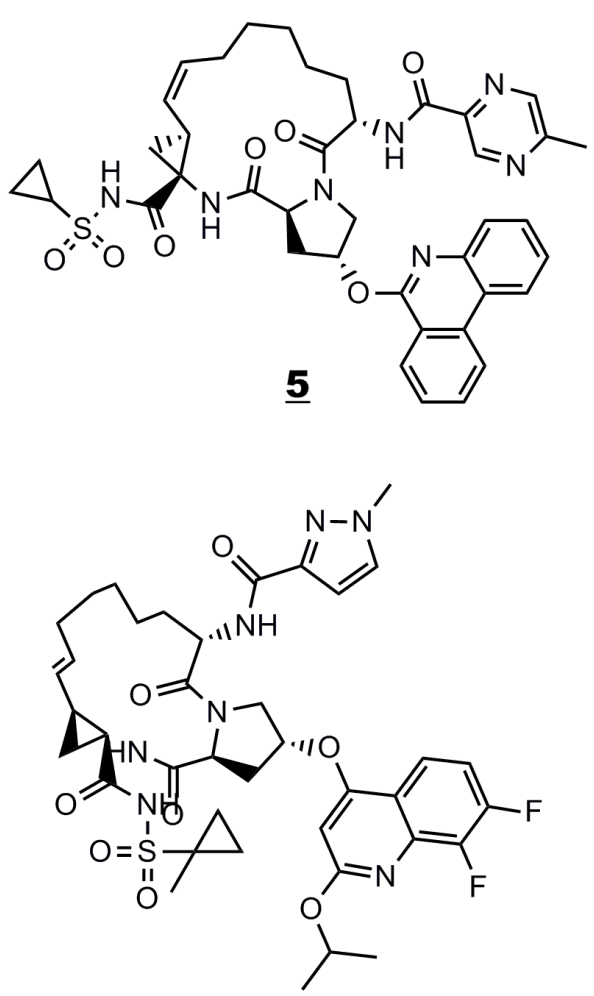

(c)

$\underline{7}$<smiles>COC(=O)NC(C(=O)N1CCCC1c1ncc(-c2ccc3c(c2)O[C@@H](c2ccccc2)n2c-3cc3cc(-c4cnc(N5CCCC5)[nH]4)ccc32)[nH]1)C(C)C(C)C</smiles>

$\underline{8}$ 


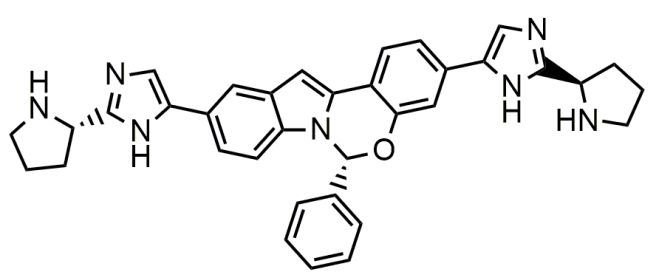

$\underline{9}$

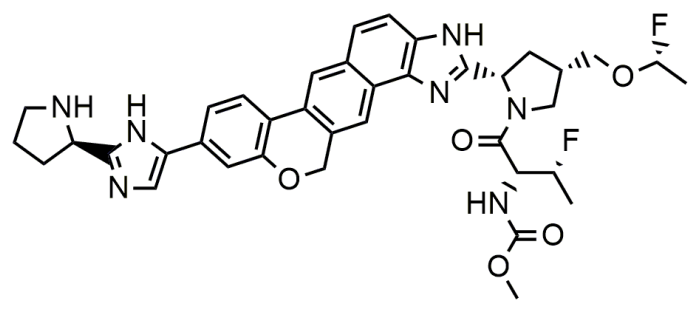

10

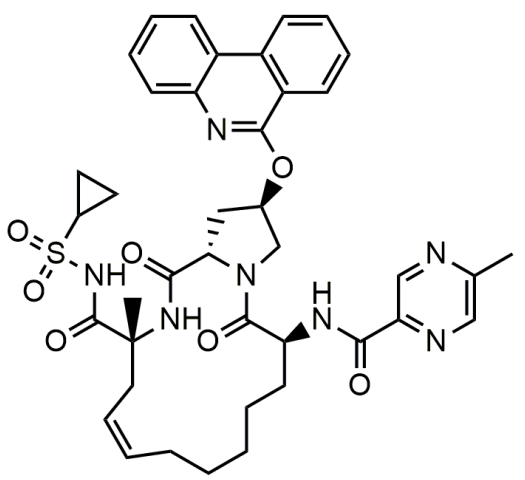

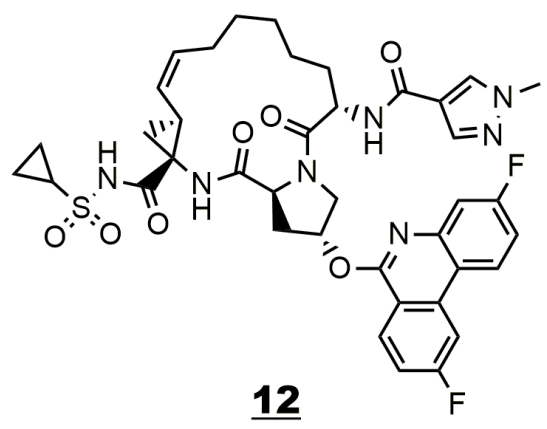

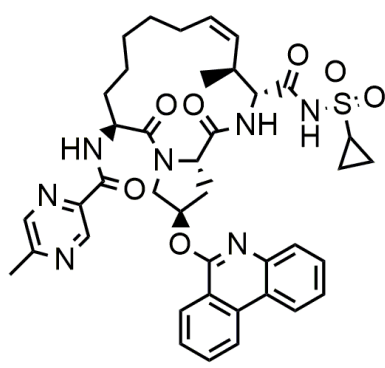

13

11 
TABLE 2: Binding affinity data of inhibitors $\underline{1}$ to $\underline{13}$ against $6 \mathrm{MO}$ J, global reactivity descriptors, $\mathrm{P}_{\mathrm{kd}}\left(\mathrm{k}_{\mathrm{d}}\right.$ dissociation constants) and binding free energies ( $\Delta G_{\text {bind }}$ ).

\begin{tabular}{|c|c|c|c|c|c|c|c|c|c|}
\hline$\#$ & Compound $^{\mathrm{a}}$ & $\begin{array}{l}\text { HOMO - LUMO } \\
\text { Energy Gap (a.u) }\end{array}$ & $\begin{array}{l}\text { Hardness } \\
\text { (n) }\end{array}$ & $\begin{array}{c}\text { Softness } \\
(\mathrm{s})\end{array}$ & $\begin{array}{c}\text { Chemical } \\
\text { Potential }(\mu)\end{array}$ & $\begin{array}{c}\text { Electrophilicity } \\
\text { Index }(\omega)\end{array}$ & $\mathbf{P}_{\mathbf{k d}}$ & $\begin{array}{c}\text { Binding } \\
\text { Affinity } \\
(\text { ADFR) } \\
\left(\text { kcal.mol }^{-1}\right)\end{array}$ & $\begin{array}{c}\text { Binding } \\
\text { Affinity } \\
\text { (Vina) } \\
\left(\text { kcal.mol }^{-1}\right)\end{array}$ \\
\hline 1 & CID 132111205 & 0.2776 & 0.1388 & 7.2037 & -0.1754 & 0.1109 & 7.34 & -7.9 & -9.5 \\
\hline 2 & daclatasvir & 0.2779 & 0.1389 & 7.1972 & -0.1708 & 0.1050 & 6.53 & -9.0 & -9.7 \\
\hline 3 & CID 135195163 & 0.2805 & 0.1403 & 7.1293 & -0.1697 & 0.1026 & 8.30 & -9.0 & -10.2 \\
\hline 4 & setrobuvir & 0.2986 & 0.1493 & 6.6989 & -0.1770 & 0.1049 & 6.39 & -9.6 & -10.2 \\
\hline 5 & paritaprevir & 0.2999 & 0.1499 & 6.6692 & -0.1824 & 0.1109 & 6.77 & -10.2 & -10.2 \\
\hline 6 & CID 117896834 & 0.2980 & 0.1490 & 6.7108 & -0.1962 & 0.1292 & 5.98 & -9.0 & -10.6 \\
\hline 7 & CID 135976538 & 0.2932 & 0.1466 & 6.8211 & -0.1901 & 0.1232 & 6.53 & -9.4 & -10.7 \\
\hline
\end{tabular}


TABLE 2 (continued): Binding affinity data of inhibitors $\underline{1}$ to $\underline{13}$ against $6 \mathrm{M} 0 \mathrm{~J}$, global reactivity descriptors, $\mathrm{P}_{\mathrm{kd}}\left(\mathrm{k}_{\mathrm{d}}\right.$ dissociation constants) and binding free energies $\left(\Delta G_{\text {bind }}\right)$.

\begin{tabular}{|c|c|c|c|c|c|c|c|c|c|}
\hline \# & Compound $^{a}$ & $\begin{array}{c}\text { HOMO - LUMO } \\
\text { Energy Gap (a.u) }\end{array}$ & $\begin{array}{c}\text { Hardness } \\
\text { (n) }\end{array}$ & $\begin{array}{c}\text { Softness } \\
\text { (s) }\end{array}$ & $\begin{array}{l}\text { Chemical } \\
\text { Potential }(\mu)\end{array}$ & $\begin{array}{c}\text { Electrophilicity } \\
\operatorname{Index}(\omega)\end{array}$ & $\mathbf{P}_{\mathbf{k d}}$ & $\begin{array}{c}\text { Binding } \\
\text { Affinity } \\
\text { (ADFR) } \\
\left(\text { kcal.mol }^{-1}\right)\end{array}$ & $\begin{array}{c}\text { Binding } \\
\text { Affinity } \\
\text { (Vina) } \\
\text { (kcal.mol }{ }^{-1} \text { ) }\end{array}$ \\
\hline 8 & elbasvir & 0.2766 & 0.1383 & 7.2297 & -0.1711 & 0.1059 & 7.55 & -10.3 & -10.8 \\
\hline 9 & CID 122523225 & 0.2745 & 0.1373 & 7.2850 & -0.1748 & 0.1113 & 6.04 & -11.6 & -10.8 \\
\hline 10 & CID 132182097 & 0.2769 & 0.1384 & 7.2235 & -0.1667 & 0.1004 & 8.50 & -9.1 & -11.2 \\
\hline 11 & CID 131982844 & 0.2938 & 0.1469 & 6.8077 & -0.1833 & 0.1144 & 6.86 & -10.4 & -11.3 \\
\hline 12 & CID 117860584 & 0.3011 & 0.1506 & 6.6413 & -0.1893 & 0.1190 & 7.22 & -10.0 & -11.5 \\
\hline 13 & CID 132247343 & 0.2969 & 0.1484 & 6.7374 & -0.1844 & 0.1145 & 6.13 & -9.5 & -11.5 \\
\hline & Acetaminophen $^{b}$ & & & & & & & -5.4 & -6.6 \\
\hline & Darunavir ${ }^{c}$ & & & & & & & -8.2 & -8.5 \\
\hline
\end{tabular}

a CiD's are compound identifier numbers in PubChem. $\quad$ b negative control $\quad c$ positive control


ring of $\underline{\mathbf{8}}$ and PHE390 and PHE40 and an alkyl bonding interaction with ARG393 (Fig. 4 and Table A1). Compounds in the low inhibitor category show less prominent interactions with the protein comparing with those in the other category. Hydrogen bonding - including
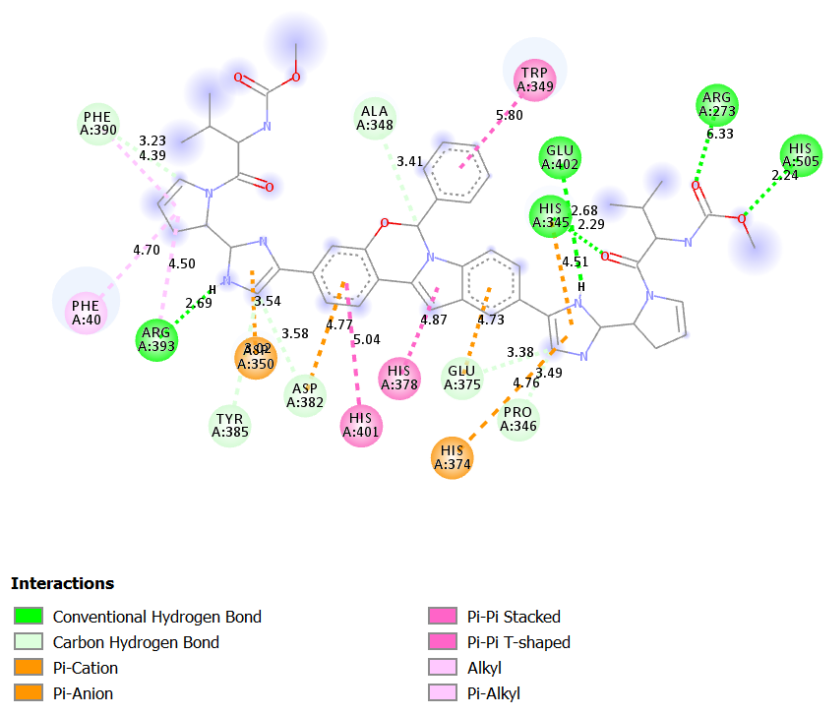

Figure 4. Docking interactions of elbasvir $\underline{8}$ (Tables $1 \&$ 2) with 6M0J (expanded version in Appendix A).

hydrogen bonds $<2.3 \AA$ - alkyl and Pi alkyl bonding is also observed but with the exception of $\underline{\mathbf{3}}$ and $\underline{\mathbf{4}}$ lack Pi-
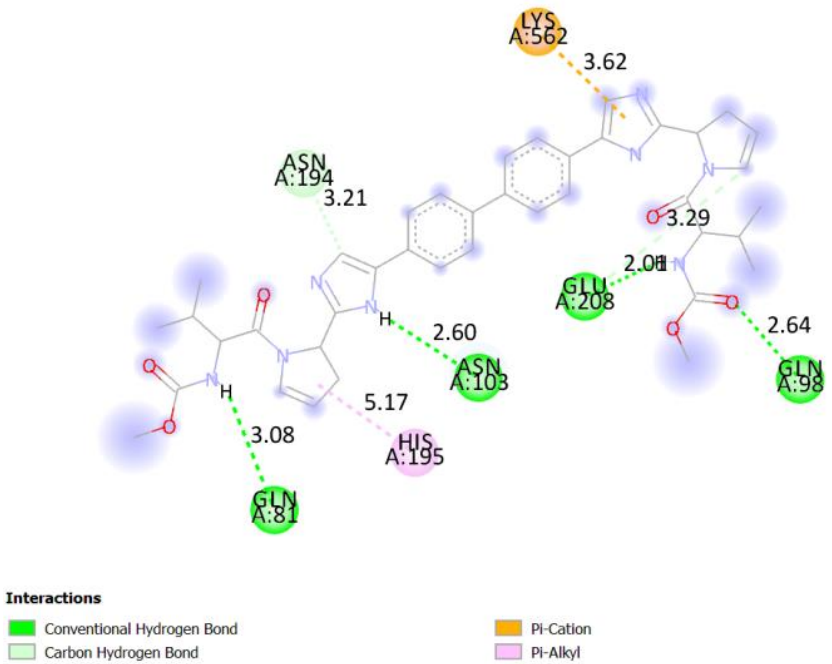

Figure 5. Docking interactions of daclatasvir $\underline{2}$ (Tables 1 \& 2) with 6M0J.

Pi stacked interactions (Table A1). Daclatasvir $\underline{\mathbf{2}}$ is a typical example of the compounds in this category (Fig. 5). Several hydrogen bonds are observed with the one between the N-H hydrogen of the acetamido group and GLU208 at a distance of $2.0 \AA$. A Pi-Alkyl interaction is formed between the pyrolidine ring of the ligand and HIS195 of the protein.

Drug (ligand) interactions with 6M0J (protein) was further studied by electrostatic potential analysis on the drugs molecular surface. The value of electrostatic calculations for understanding and predicting molecular properties has been recognized for decades. It is wellknown that molecular electrostatics can be predictive of a molecule's chemical reactivity and its ability to form certain types of interactions. Electrostatic potential surfaces (ESP) are used to visualize the electrostatic nature of molecules. ${ }^{51-52}$ Drugs from the strong (compound $\underline{\mathbf{1 2}}$ ) and weak inhibitor categories (daclatasvir $\underline{\mathbf{2}}$ ) with respect to their binding affinity towards $6 \mathrm{M} 0 \mathrm{~J}$ were selected from Table 2 and their wavefunctions produced at the B97-3c/def2-mTZVP ${ }^{38}$ level. The electrostatic potential of the above compounds on their vdW surfaces were computed using the above wavefunctions. As the final part of ESP analysis, the molecular surface area in each ESP range was calculated in order to quantitatively determine ESP distribution on the whole molecular surface. ${ }^{43}$ The results obtained surface areas $\left(\AA^{2}\right)$ and corresponding electrostatic potentials ESP $\left(\mathrm{kcal}^{\mathrm{mol}}{ }^{-1}\right)$ were used to plot histogram graphs of $\underline{\mathbf{2}}$ and $\underline{\mathbf{1 2}}$ (Figs. 6 and 7 respectively).

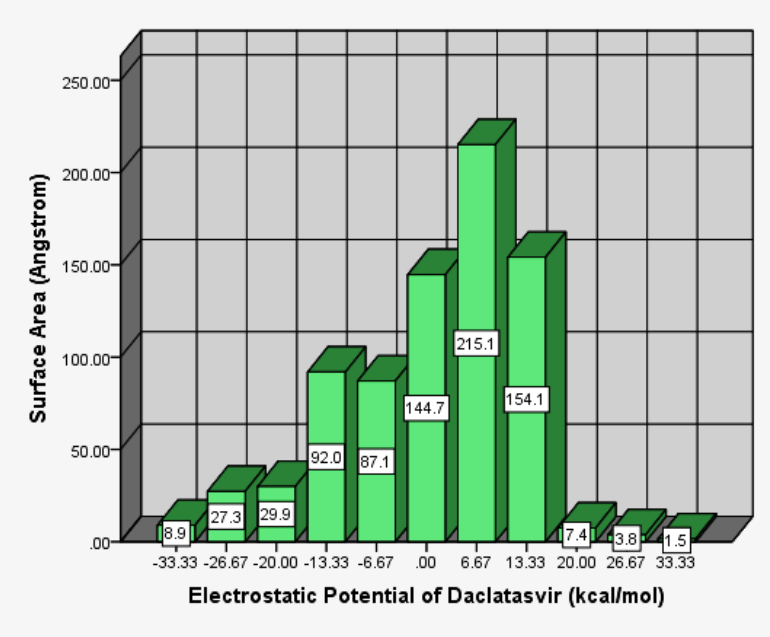

Figure 6. Surface area $\left(\AA^{2}\right)$ in each electrostatic potential (kcal.mol ${ }^{-1}$ ) range on the vdW surface of daclatasvir $\underline{\mathbf{2}}$.

From the graphs in Figs. 6 and 7 it can be seen that there is a large portion of molecular surface having low ESP values, namely from $-20 \mathrm{kcal}^{\mathrm{mol}}{ }^{-1}$ to $20 \mathrm{kcal}^{\mathrm{mol}}{ }^{-1}$. There are also small areas having remarkable positive and negative ESP values, corresponding to the regions closed to the global ESP minimum and maximum, re- 
spectively. These global surface maxima and minima were found to be 0.06617912 a.u. $\left(41.528059 \mathrm{kcal}_{\mathrm{mol}}{ }^{-1}\right)$

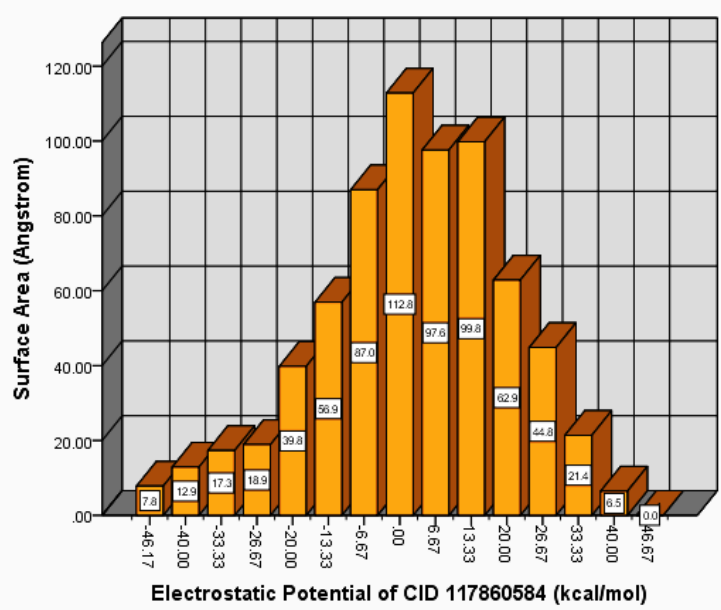

Figure 7. Surface area $\left(\AA^{2}\right)$ in each electrostatic potential (kcal.mol-1 $)$ range on the vdW surface of compound $\underline{12}$.

and -0.07777287 a.u. ( $\left.-48.803254 \mathrm{kcal}^{\mathrm{mol}} \mathrm{m}^{-1}\right)$ for compound $\underline{\mathbf{1 2}}$, and 0.05207833 a.u. $\left(32.679670 \mathrm{kcal}^{\mathrm{mol}}{ }^{-1}\right.$ ) and -0.05769414 a.u. $\left(-36.203650 \mathrm{kcal}^{\mathrm{mol}} \mathrm{l}^{-1}\right)$ for compound $\underline{\mathbf{2}}$ and their observed differences suggested that the ESP distribution on the vdW surface fluctuates more remarkably in the former. Compound $\underline{\mathbf{1 2}}$ shows higher positive charge density than daclatasvir $\underline{\underline{2}}$ and a higher

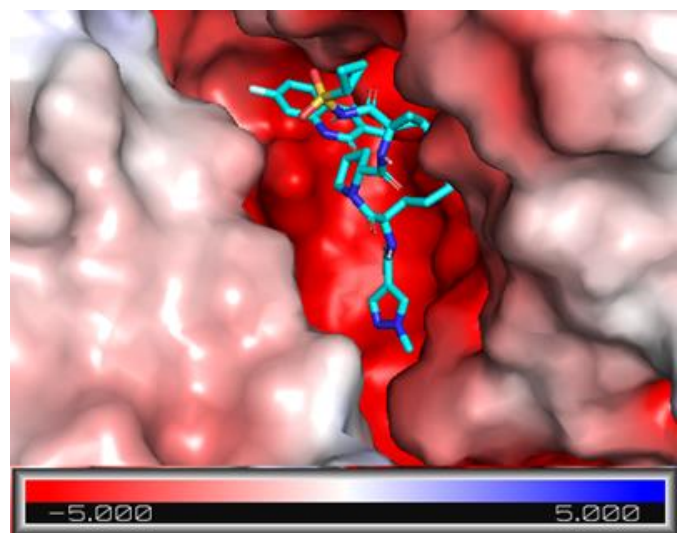

Figure 8. Compound 12 inside the negatively charged 6M0J binding pocket.

overall average charge equal to 0.00300125 a.u. $\left(1.88332 \mathrm{kcal}^{\mathrm{mol}}{ }^{-1}\right)$ compared to an overall average charge equal to 0.00061890 a.u. $\left(0.38837 \mathrm{kcal}^{\mathrm{mol}}{ }^{-1}\right)$ of $\underline{2}$ (Table 3 ). This higher observed overall average charge - consistent with the higher electrophilicity shown (Table 2) - coupled with other factors may explain the higher attraction shown by 12 towards or inside the negatively charged protein binding pocket (Fig. 8). The ESP plots of compounds $\underline{\mathbf{2}}$ and $\underline{12}$ mapped onto the electron density surface for the ground state are shown in Fig. 9 and Fig. 10 respectively. Electron rich (negative ESP) and electron deficient areas (positive ESP) are indicated with red and white color respectively. Electron rich areas are over oxygen, sulfur, nitrogen and fluorine atoms of 12 (Fig. 10) and these atoms participate in the docking interactions of this drug with 6M0J (Fig. 2). Positive potential appears over hydrogen atoms and the alkyl group and this is also consistent with the reactivity shown and the hydrogen bonds formed (Fig. 2). Similarly, The ESP plot of compound $\underline{\mathbf{2}}$ is very effective to predict the reactive sites of the molecule with the target protein $6 \mathrm{MOJ}^{52}$ (Fig. 5 and Fig. 9). Electron rich areas appear over oxygen and nitrogen, and these atoms participate in hydrogen bonds. Electron poor areas are observed over hydrogen atoms and alkyl groups. These results demonstrate that weak interactions between molecules, including $\mathrm{H}$ bonds and halogen bonds, can be predicted and explained by analyzing the magnitude and positions of the minima and maxima in an electrostatic potential (ESP) on the molecular vdW surface. ${ }^{53}$

The formed ligand (drug in Table 2) - receptor (6M0J) complexes reveal that pi-pi stacking, pi-alkyl and halogen bonds are able to increase the binding affinity and explain the differences in binding energies. Furthermore, to evaluate the stability of the formed protein - ligand complexes, these structures were subjected to fully solvated atomistic molecular dynamics (MD) simulations using $\mathrm{VMD}^{54}$ and NAMD. ${ }^{55}$ MD simulations were conducted at $310 \mathrm{~K}$ for $30 \mathrm{~ns}$. Structural fluctuations of protein and the ligands are indicated by variation in the root mean square variation (RMSD). The RMSD of the free protein remained stable between $8 \mathrm{~ns}$ and $22 \mathrm{~ns}$ at $2 \AA$ and then slightly increased and fluctuated around $2.1 \AA$ from 22 to $30 \mathrm{~ns}$ (Fig. 11). The RMSD of the 6M0J and $\underline{\mathbf{1 3}}$ complex was balanced after $24 \mathrm{~ns}$ and slightly fluctuated between 2.2 and $2.3 \AA$ while the RMSD plot of the $6 \mathrm{MOJ}$ and $\underline{\mathbf{1 2}}$ initially increased for about $10 \mathrm{~ns}$ and then slightly fluctuated around $2 \AA$. The RMSD of $6 \mathrm{M} 0 \mathrm{~J}$ and $\underline{12}$ showed that this complex had the greatest effect on protein's stability (Fig. 11). The RMSD of 6M0J and $\underline{\mathbf{1 1}}$ increased for about $25 \mathrm{~ns}$ and then fluctuated between 2.2 and $2.4 \AA$. As depicted in Fig. 11 the RMSD of the $6 \mathrm{M} 0 \mathrm{~J}$ and $\mathbf{1 0}$ complex was balanced after $20 \mathrm{~ns}$ and then slightly fluctuated around $2.10 \AA$. MD analysis revealed that the studied complexes have shown structural stability during the runs.

The ADMET profile of the hit compounds $\underline{\mathbf{1 0}}-\underline{\mathbf{1 3}}$ was computed in silico using the web-based tool admetSAR. ${ }^{56}$ These compounds were found to be within the reference range considering the rule of five, their water solubility $(\log S)$, human colon adenocarcinoma (Caco-2) permeability, blood to brain barrier (BBB) and human intestinal absorption (HIA) (Table A2, Appendix A). 
TABLE 3: Surface analysis Electrostatic Potential Values (ESP) (units a.u.) computed for compounds $\underline{2}$ and $\underline{12}$ (Table 2) using the Multiwfn Analyzer ${ }^{43}$

ESP Values (a.u.)
Compound 2

0.052078

$-0.057694$

0.00061890

0.01292542

$-0.01804650$

0.01484047

\section{Compound $\underline{12}$}

$\begin{array}{ccc}\text { Maximum Value } & 0.052078 & 0.066179 \\ \text { Minimum Value } & -0.057694 & -0.077772 \\ \text { Overall Average Value } & 0.00061890 & 0.00300125 \\ \text { Positive Average Value } & 0.01292542 & 0.02232525 \\ \text { Negative Average Value } & -0.01804650 & -0.02198169 \\ \text { Internal Charge Separation } & 0.01484047 & 0.02193806\end{array}$

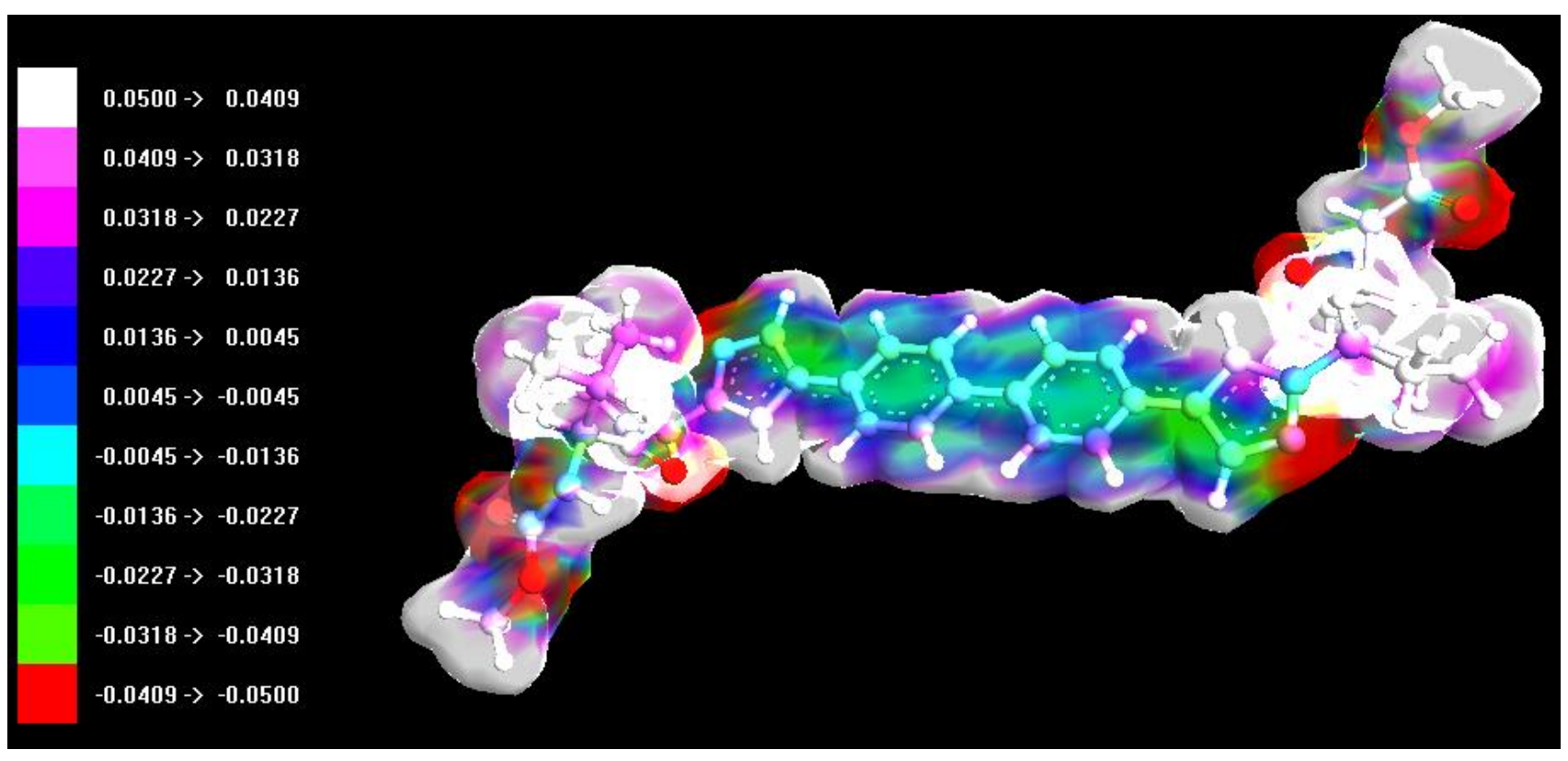

Figure 9. Electrostatic potential (ESP) mapped electron density surface of compound $\underline{2}$ at the PM3 level 


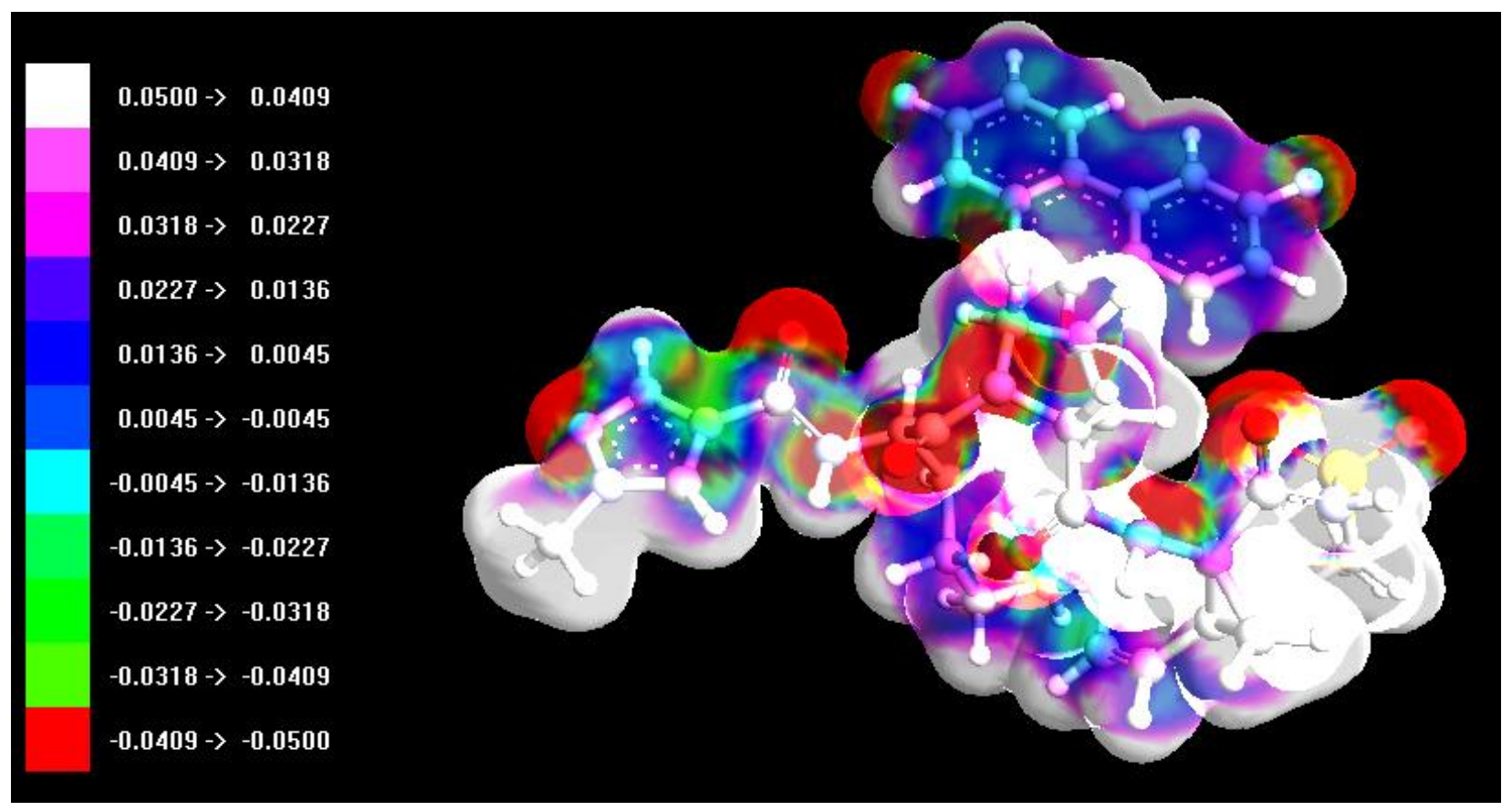

Figure 10. Electrostatic potential (ESP) mapped electron density surface of compound 12 at the PM3 level

In summary, among the drugs of Table 2 increased affinity for $6 \mathrm{M} 0 \mathrm{~J}$ exhibit all those with large compound volume, relatively higher electrophilicity index, higher overall average charge, with aromatic rings and heteroatoms that participate in hydrogen bonding. Based on the binding energy, the best compounds were discovered to be the elbavir analogue $\underline{\mathbf{1 0}}\left(-11.2 \mathrm{kcal}_{\mathrm{mol}}{ }^{-1}\right)$ and the patitaprevir analogues $\underline{\mathbf{1 1}}, \underline{\mathbf{1 2}}$ and $\underline{\mathbf{1 3}}(-11.3,-11.5$, $11.5 \mathrm{kcal}^{\mathrm{mol}}{ }^{-1}$ respectively). Further optimization of these compounds can result in a more effective drug able to stop this newly emerged infection.

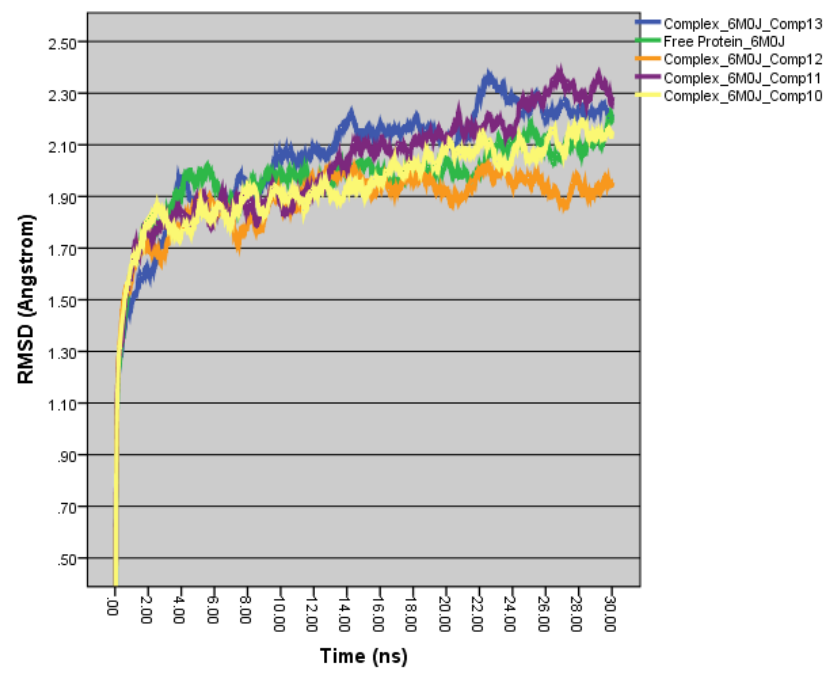

Figure 11. MD simulation RMSD plots ( $30 \mathrm{~ns}, 310 \mathrm{~K}$ ) of free $6 \mathrm{MOJ}$ and of complexes of $6 \mathrm{MOJ}$ with compounds $\underline{10-13}$.

\section{CONCLUSIONS}

The infectious respiratory disease COVID-19 is rapidly expanding throughout the world and has become a serious threat to global health. Considering the time required to develop a new approved drug, drug repurposing seems the most appealing, safe and straightforward approach. In this study FDA approved HCV antiviral drugs and their structural analogues in clinical trials were tested for their inhibitory properties towards the COVID-19 protein (6M0J) using a virtual screening approach and computational chemistry methods. The most stable structures and the corresponding binding affinities of thirteen such antiviral compounds were obtained. Molecular docking calculations, ESP analysis, frontier molecular orbital theory and global reactivity descriptors were used to hypothesize the bioactivity of these drugs against the COVID19 protein (6M0J). Compounds $\underline{\mathbf{6}}$ to $\underline{\mathbf{9}}$ - among them elbasvir - showed remarkable binding affinities (-10.6 to $\left.-10.8 \mathrm{kcal}^{\mathrm{mol}}{ }^{-1}\right)$ with 6M0J. Moreover, four compounds $\underline{10}$ to $\underline{\mathbf{1 3}}$ (Table 2) - elbasvir and paritaprevir analogues - showed excellent binding interactions -11.2 to $-11.5 \mathrm{kcal}^{\mathrm{mol}}{ }^{-1}$ - for use against the newly emerged strain of coronavirus. Furthermore, trajectories analysis revealed that the studied complexes have shown structural stability during the MD runs. Therefore, it is concluded that these four top scoring compounds may act as lead compounds for further experimental validation, clinical trials and for the development of more potent antiviral agents against the SARS-CoV-2. 


\section{DISCLOSURE STATEMENT}

No potential conflict of interest is reported by the author.

\section{ORCID}

\section{K. G. Kalamatianos (D) 0000-0002-0276-6531}

\section{CONTACT}

\section{K. G. Kalamatianos $ه$ kgkalamatianos@gmail.com Analytical Chemistry \& Toxicology Laboratory, I.Y.A., Athens, Greece}

\section{REFERENCES}

${ }^{1}$ Gorbalenya, A.E.; Baker, S.C.; Baric, R.S. et al. The species severe acute respiratory syndrome-related coronavirus: classifying 2019$\mathrm{nCoV}$ and naming it SARS-CoV-2. Nat Microbiol, 2020, 5, 536-544.

${ }^{2}$ Kupferschmidt, K.; Cohen, J. Will novel virus go pandemic or be contained? Science, 2020, 367 (6478), 610-611.

${ }^{3}$ Coronavirus Disease (COVID-2019) Situation Reports 1-45; World Health Organization, 2020.

${ }^{4}$ Anthony, S. J.; Johnson, C. K.; Greig, D. J.; Kramer, S.; Che, X.; Wells, H.; Hicks, A. L.; Joly, D. O.; Wolfe, N. D.; Daszak, P.; Karesh, W.; Lipkin, W. I.; Morse, S. S.; Mazet, J. A. K.; Goldstein, T. Global patterns in coronavirus diversity. Virus Evol, 2017, 3 (1), vex012, DOI: 10.1093/ve/vex012.

${ }^{5}$ Su, S.; Wong, G.; Shi, W.; Liu, J.; Lai, A. C.K.; Zhou, J.; Liu, W.; Bi, Y.; Gao, G. F. Epidemiology, genetic recombination, and pathogenesis of coronaviruses. Trends Microbiol., 2016, 24 (6), 490- 502, DOI: $10.1016 /$ j.tim.2016.03.

${ }^{6}$ Zhu, N.; Zhang, D.; Wang, W.; Li, X.; Yang, B.; Song, J.; Zhao, X.; Huang, B.; Shi, W.; Lu, R.; Niu, P.; Zhan, F.; Ma, X.; Wang, D.; Xu, W.; Wu, G.; Gao, G. F.; Tan, W. A novel coronavirus from patients with pneumonia in China, 2019. N. Engl. J. Med., 2020, 382 (8), 727 733, DOI: 10.1056/NEJMoa2001017.

${ }^{7}$ Tang, B.; Bragazzi, N. L.; Li, Q.; Tang, S.; Xiao, Y.; Wu, J. An updated estimation of the risk of transmission of the novel coronavirus (2019-nCov). Infect Dis Model, 2020, 5, 248- 255, DOI: 10.1016/j.idm.2020.02.001

${ }^{8}$ Zhou, P.; Yang, X. L.; Wang, X.G.; Hu, B.; Zhang, L; Zhang, W. et al. A pneumonia outbreak associated with a new coronavirus of probable bat origin, Nature, 2020 579, 270-273 https://doi.org/10.1038 /s41586-020-2012-7.

${ }^{9}$ BBC News Covid: Will there be more than one coronavirus vaccine? https://www.bbc.com/news/health-51665497.

${ }^{10}$ Ghosh, A.K.; Brindisi, M.; Shahabi, D.; Chapman, M.E.; Mesecar, A.D. Drug Development and Medicinal Chemistry Efforts toward SARS-Coronavirus and Covid- 19 Therapeutics. ChemMedChem., 2020, 15, 1-27, DOI:10.1002/cmdc.202000223.

11 Elfiky, AA. Ribavirin, Remdesivir, Sofosbuvir, Galidesivir, and Tenofovir against SARS-CoV-2 RNA dependent RNA polymerase (RdRp): A molecular docking study. Life Sci., 2020, 253, 117592117598, DOI: 10.1016/j.lfs.2020.117592.

${ }^{12}$ Shah, B; Modi, P; Sagar, SR. In silico studies on therapeutic agents for COVID-19: Drug repurposing approach. Life Sci., 2020, 252, 117652-117664, DOI: 10.1016/j.lfs.2020.117652.

${ }^{13}$ Elfiky, AA. Anti-HCV, nucleotide inhibitors, repurposing against COVID-19. Life Sci., 2020, 248, 117477-117483, DOI: $\underline{10.1016 / j .1 f s .2020 .117477 .}$.
${ }^{14}$ Kumar, S.; Sharma, P.P.; Shankar, U; Kumar, D.; Joshi, S.K; Pena, L.; Durvasula, R.; Kumar, A.; Kempaiah, P.; Poonam; Rathi, B. scovery of New Hydroxyethylamine Analogs against 3CLpro Protein Target of SARS-CoV-2: Molecular Docking, Molecular Dynamics Simulation, and Structure-Activity Relationship Studies. J. Chem. Inf. Model., 2020, DOI: 10.1021/acs.jcim.0c00326.

15 Elmezayen, A.D; Al-Obaidi, A.; Şahin, A.T.; Yelekçi K. Drug repurposing for coronavirus (COVID-19): in silico screening of known drugs against coronavirus 3CL hydrolase and protease enzymes. J. Biomol Struct. Dyn., 2020, 1-13, DOI:10.1080/07391102.2020.1758791.

${ }^{16}$ Asai, A.; Konno, M.; Ozaki, M.; Otsuka, C.; Vecchione, A.; Arai, T.; Kitagawa, T.; Ofusa, K.; Yabumoto, M.; Hirotsu, T.; Taniguchi, M.; Eguchi, H.; Doki, Y.; Ishii, H. COVID-19 Drug Discovery Using Intensive Approaches. Int. J. Mol. Sci., 2020, 21, 2839-2848, DOI:10.3390/ijms21082839.

${ }^{17}$ Rohit, B; Raj, K.N; Ravindra K. R. Drug Repurposing: A Promising Tool in Drug Discovery Against Cov-19. Biomed. J. Sci. \& Tech. Res., 2020, 28(5), 21913-21915.

${ }^{18}$ Wang J. Fast Identification of Possible Drug Treatment of Coronavirus Disease-19 (COVID-19) through Computational Drug Repurposing Study. J. Chem. Inf. Model. 2020; 60, 3277-3286, DOI:10.1021/acs.jcim.0c00179.

${ }^{19}$ Pant S, Singh M, Ravichandiran V, Murty USN, Srivastava HK. Peptide-like and small-molecule inhibitors against Covid-19. J Biomol. Struct. Dyn.,2020, 1-10, DOI:10.1080/073911002,2020,1757

20 Joshi S, Joshi M, Degani MS. Tackling SARS-CoV-2: proposed targets and repurposed drugs. Future Med Chem., 2020, DOI: 10.4155/fmc-2020-0147.

${ }^{21}$ Adebambo, K. Computational Investigation of the Interaction of Anti-Influenza Drugs with CoVID-19 Protein. Computational Molecular Bioscience, 2020, 10, 45-60.

${ }_{22}^{22}$ Sharp, Kumar; Dange, Dr. Shubhangi In-Silico FDA-Approved Drug Repurposing to Find the Possible Treatment of Coronavirus Disease-19 (COVID-19), 2020, ChemRxiv. Preprint. https://doi.org/10.26434/chemrxiv.12340718.v1.

${ }^{23}$ Rajbhar, Priyanka; Singh, Dikshant; Yadav, Ruchi Repurposing of SARS Inhibitors Against COVID19, 2020, ChemRxiv. Preprint. https://doi.org/10.26434/chemrxiv.12155361.v1.

${ }^{24}$ Sadeghi, A; Asgari, A; Norouzi, A; Kheiri, Z; Anushirvani, A; Montazeri, M; Hosamirudsai, H; Afhami, S; Akbarpour, E; Aliannejad, R; Radmard, AR; Davarpanah, AH, Levi, J; Wentzel, H; Qavi, A; Garratt, A; Simmons, B; Hill, A; Merat, S. Sofosbuvir and daclatasvir compared with standard of care in the treatment of patients admitted to hospital with moderate or severe coronavirus infection (COVID-19): a randomized controlled trial. J Antimicrob Chemother. 2020 75(11), 3379-3385, DOI: 10.1093/jac/dkaa334.

${ }^{25}$ Kalamatianos, K. G. Drug Repurposing for (COVID-19): In Silico Screening of Known Drugs Against the SARS-CoV-2 Spike Protein Bound to Angiotensin Converting Enzyme 2 (6M0J). ChemRxiv., 2020, Preprint, https://doi.org/10.26434/chemrxiv.12857678.v1.

${ }^{26}$ Stewart, J.J.P. Optimization of parameters for semiempirical methods I. Method. J. Comput. Chem. 1989, 10, 209-220, DOI: 10.1002/jcc.540100208.

${ }^{27}$ Stewart, J.J.P. Optimization of parameters for semiempirical methods II. Applications. J. Comput. Chem., 1989, 10, 221-264, DOI: 10.1002/jcc.540100209.

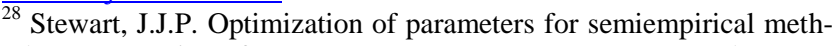
ods. III Extension of PM3 to Be, Mg, Zn, Ga, Ge, As, Se, Cd, In, Sn, $\mathrm{Sb}, \mathrm{Te}, \mathrm{Hg}, \mathrm{Tl}, \mathrm{Pb}$, and Bi. J. Comput. Chem. 1991 12, 320-341, DOI: 10.1002/jcc.540120306.

${ }^{29}$ Stewart, J.J.P. Optimization of parameters for semiempirical methods IV: extension of MNDO, AM1, and PM3 to more main group elements. J Mol Model 10, 2004 155-164, DOI: 10.1007/s00894-0040183-z.

${ }^{30}$ Sinha, L.; Prasad, O.; Narayan, V.; Shukla, SR. Raman, FT-IR spectroscopic analysis and first-order hyperpolarisability of 3benzoyl5-chlorouracil by first principles. J Mol. Simul. 2011, 37, 153163.

${ }^{31}$ Lewis, D.F.V.; Loannides, C.; Parke, D.V. Interaction of a series of nitriles with the alcohol-inducible isoform of P450: Computer analysis of structure-activity relationships. Xenobiotica. 1994, 24, 401-408. 
${ }^{32}$ Kosar, B.; Albayrak, C. Spectroscopic investigations and quantum chemical computational study of (E)-4-methoxy-2[(ptolylimino)methyl]phenol. Spectrochim Acta. 2011, 78, 160-167.

${ }^{33}$ Fukui, K. Role of frontier orbitals in chemical reactions. Science. 1982, 218, 747- 754 .

${ }^{34}$ Lan, J; Ge J; Yu, J; Shan, S; Zhou, H; Fan, S; Zhang, Q; Shi, X; Wang, Q; Zhang, L; Wang, X. Structure of the SARS-CoV-2 spike receptor-binding domain bound to the ACE2 receptor. Nature. 2020 581, 215-220, DOI:10.1038/s41586-020-2180-5

${ }^{35}$ Du, L.; He, Y.; Zhou, Y.; Liu, S.; Zheng, B.-J.; Jiang, S. The spike protein of SARS-CoV - A target for vaccine and therapeutic development. Nat. Rev. Microbiol. 2009, 7 (3), 226-236.

${ }^{36}$ Thompson, M.A. "Molecular docking using ArgusLab, an efficient shape-based search algorithm and AScore scoring function," in Proceedings of the ACS Meeting, Philadelphia, Pa, USA, March-April 2004, 172, CINF 42.

${ }^{37}$ Neese, F. The Orca program system. Comput. Mol. Sci., 2012, 2, Issue 1, 73-78.

${ }^{38}$ Brandenburg, J.G.; Bannwarth, C.; Hansen, A.; Grimme S. B97-3c: A revised lowcost variant of the B97-D density functional method. J. Chem. Phys. 2018;148(6):064104. DOI: 10.1063/1.5012601.

${ }^{39}$ Trott, O.; Olson, A. J. Software news and update AutoDockVina: Improving the speed and accuracy of docking with a new scor-ing function, efficient optimization, and multithreading. Journal of Comput. Chem., 2009, 31(2), NA-461. https://doi.org/10.1002/jcc.21334. 40 Jiménez, J.; Škalič, M.; Martínez-Rosell G., De Fabritiis, G. KDEEP: Protein-Ligand Absolute Binding Affinity Prediction via 3D-Convolutional Neural Networks. Journal of Chemical Information and Modeling 201858 (2), 287-296 DOI: 10.1021/acs.jcim.7b00650

${ }^{41}$ Seeliger, D; De Groot B.L. (2010) Conformational transitions upon ligand binding: holo-structure prediction from apo conformations. PLoS Computational Biology, 2010, 6: e1000634.

${ }^{42}$ Morris, GM; Lim-Wilby, M. (2008) Molecular Docking. In: Kukol A (Eds.). Molecular Modeling of Proteins. Humana Press, Totowa, NJ, pp. 365-382.

${ }^{43}$ Tian, L; Feiwu C. Multiwfn - A Multifunctional Wavefunction Analyzer. J. Comput. Chem., 2012, 33, 580-592.

${ }_{44}$ The PyMOL Molecular Graphics System, Version 2.0 Schrödinger, LLC.

${ }^{45}$ Karelson, M. Molecular Descriptors in QSAR/QSPR, Wiley-Interscience, 2000

${ }^{46}$ Scrocco, E; Tomasi, J. The Electrostatic Molecular Potential as a Tool for the Interpretation of Molecular Properties. In New Concepts II, Springer, 1973, 42, 95-170.

${ }^{47}$ Petrolongo, C. Quantum Chemical Study of Isolated and Interacting Molecules with Biological Activity. Gazz. Chim. Ital., 1978, 108, 445-478.

48 IBM Corp. Released 2011. IBM SPSS Statistics for Windows, Version 20.0. Armonk, NY: IBM Corp.

${ }^{49}$ Wade, R.C.; Goodford, P.J. The role of hydrogen-bonds in drug binding. Prog. Clin. Biol. Res., 1989, 289, 433-444. ${ }^{50}$ Sarwar, M.G.; Ajami, D.; Theodorakopoulos, G.; Petsalakis, I.D.; Rebek, J. Amplified Halogen Bonding in a Small Space, J.A.C.S, 2013, 135, 13672-13675.

${ }^{51}$ Weiner, P.K.; Langridge, R.; Blaney, J.M.; Schaefer, R.; Kollman, P.A. Electrostatic Potential Molecular Surfaces. Proc. Natl. Acad. Sci., 1982, 79 (12), 3754-3758.

${ }^{52}$ Okulik, N.; Jubert, A.H. Theoretical study on the structure and reactive sites of non-steroidal anti-inflammatory drugs. J. Mol. Struct. THEOCHEM2004,682,55-59.

${ }^{53}$ Tian, X.; Liu, Y.; Zhu, J.; Yu, Z.; Han, J.; Wang, Y. Probing inhibition mechanisms of adenosine deaminase by using molecular dynamics simulations. PLoS ONE, 2018 13(11): e0207234. https://doi.org/10.1371/journal.pone.0207234

${ }^{54}$ Humphrey, W.; Dalke, A.; Schulten, K. VMD: Visual Molecular Dynamics. J. Mol. Graph. 1996, 14 (1), 33-38. https://doi.org/https://doi.org/10.1016/0263-7855(96)00018-5.

${ }^{55}$ Phillips, J. C.; Hardy, D. J.; Maia, J. D. C.; Stone, J. E.; Ribeiro, J. V; Bernardi, R. C.; Buch, R.; Fiorin, G.; Hénin, J.; Jiang, W.; McGreevy, R.; Melo, M. C. R.; Radak, B. K.; Skeel, R. D.; Singharoy, A.; Wang, Y.; Roux, B.; Aksimentiev, A.; LutheySchulten, Z.; Kalé, L. V; Schulten, K.; Chipot, C.; Tajkhorshid, E.
Scalable Molecular Dynamics on CPU and GPU Architectures with NAMD. J. Chem. Phys. 2020, 153-158 (4), 44130. https://doi.org/10.1063/5.0014475.

${ }^{56}$ Yang, H.; Lou, C.; Sun, L.; Li, J.; Cai, Y.; Wang, Z.; Li, W.; Liu, G.; Tang, Y. AdmetSAR 2.0: Web-service for prediction and optimization of chemical ADMET properties. Bioinformatics 2019; 35 (6), 1067-1069. 
APPENDIX A 


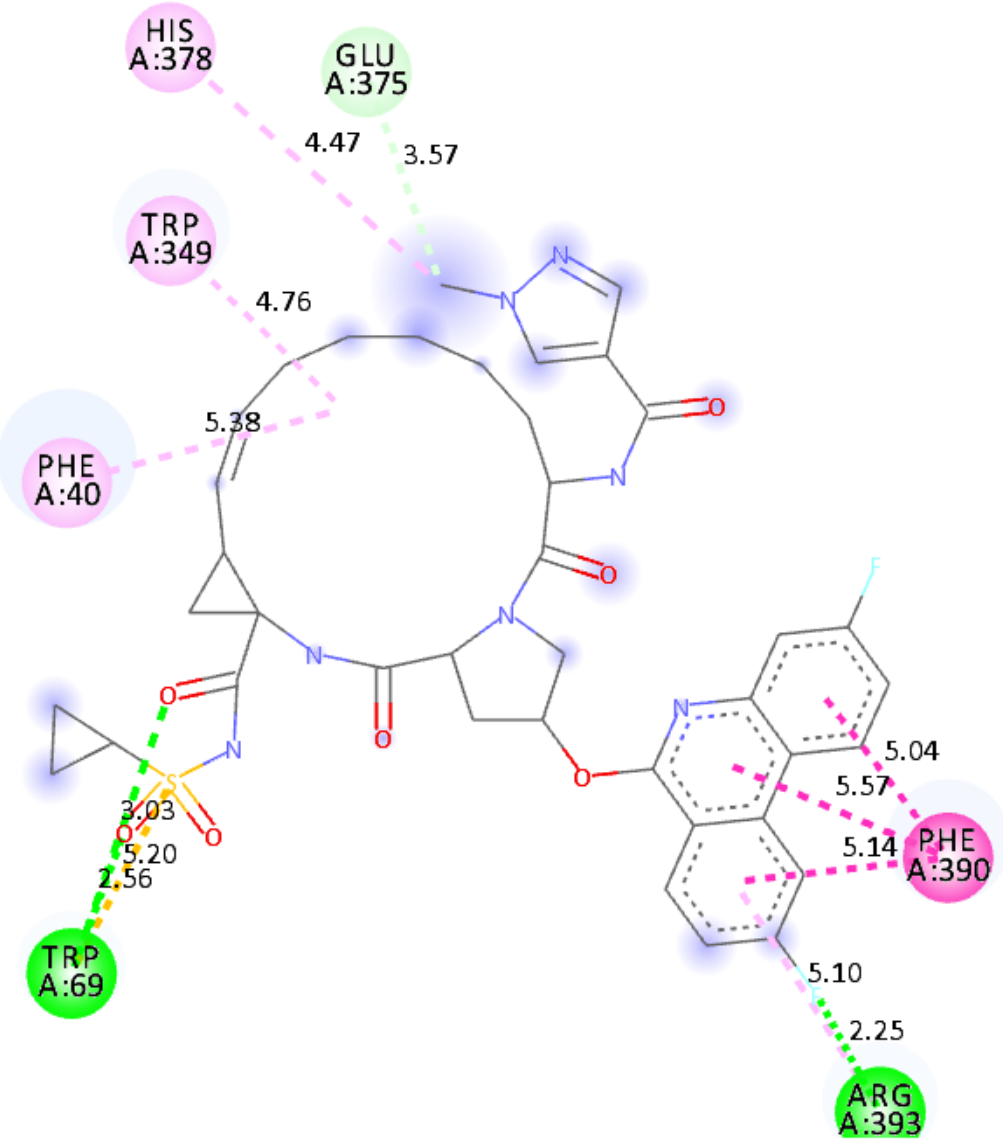

\section{Interactions}

$\square$ Conventional Hydrogen Bond

Carbon Hydrogen Bond

Pi-Pi Stacked

$\square$ Pi-Sulfur

Figure 2 (expanded version). Docking interactions of compound $\underline{12}$ (Tables 1 \& 2) with 6M0J. 


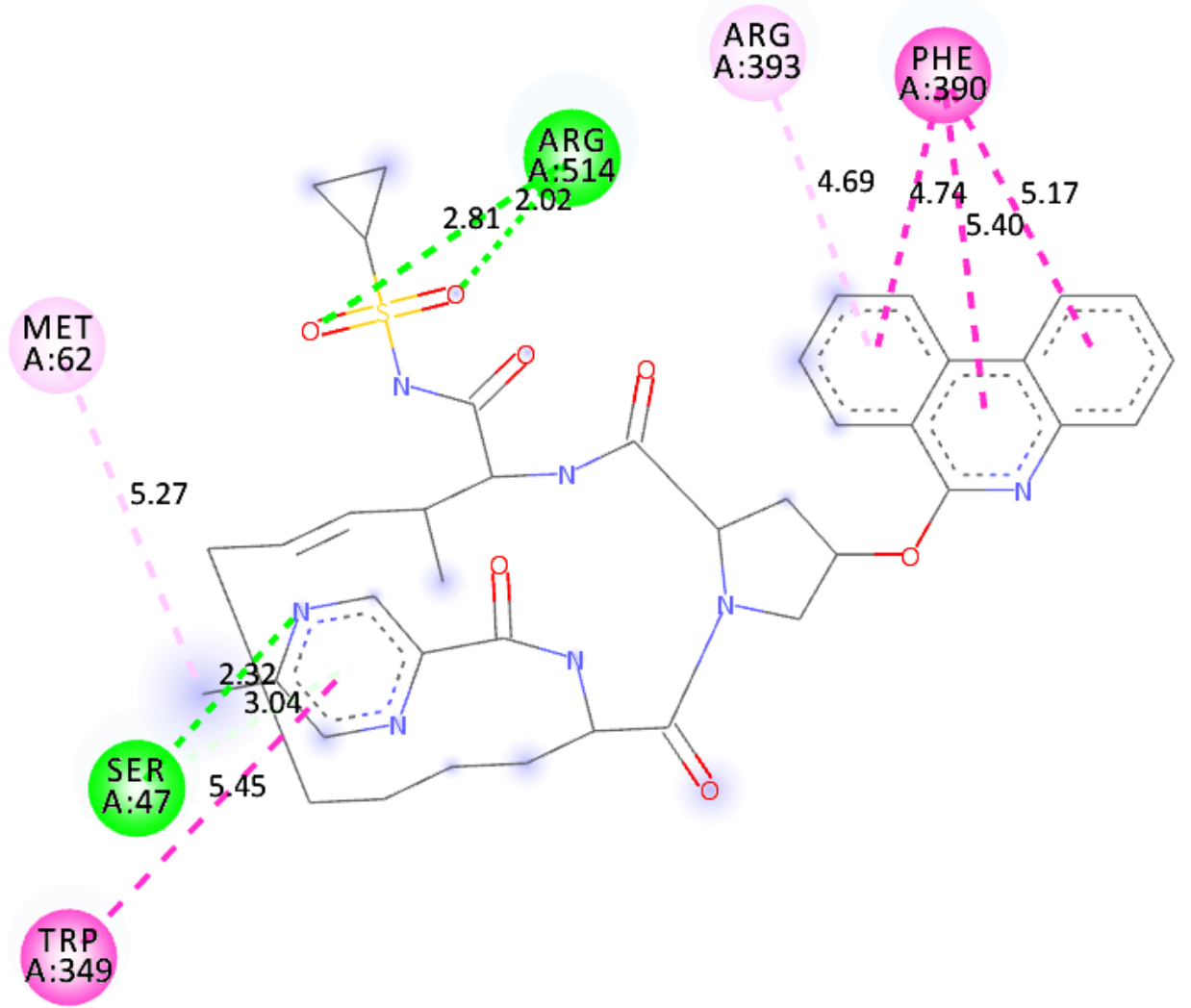

\section{Interactions}

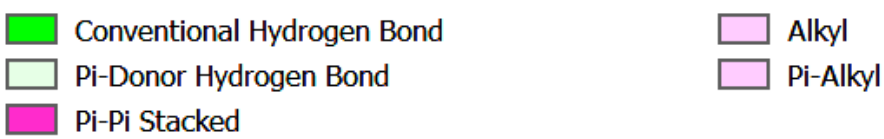

Figure 3 (expanded version). Docking interactions of compound $\underline{13}$ (Tables 1 \& 2) with 6M0J. 


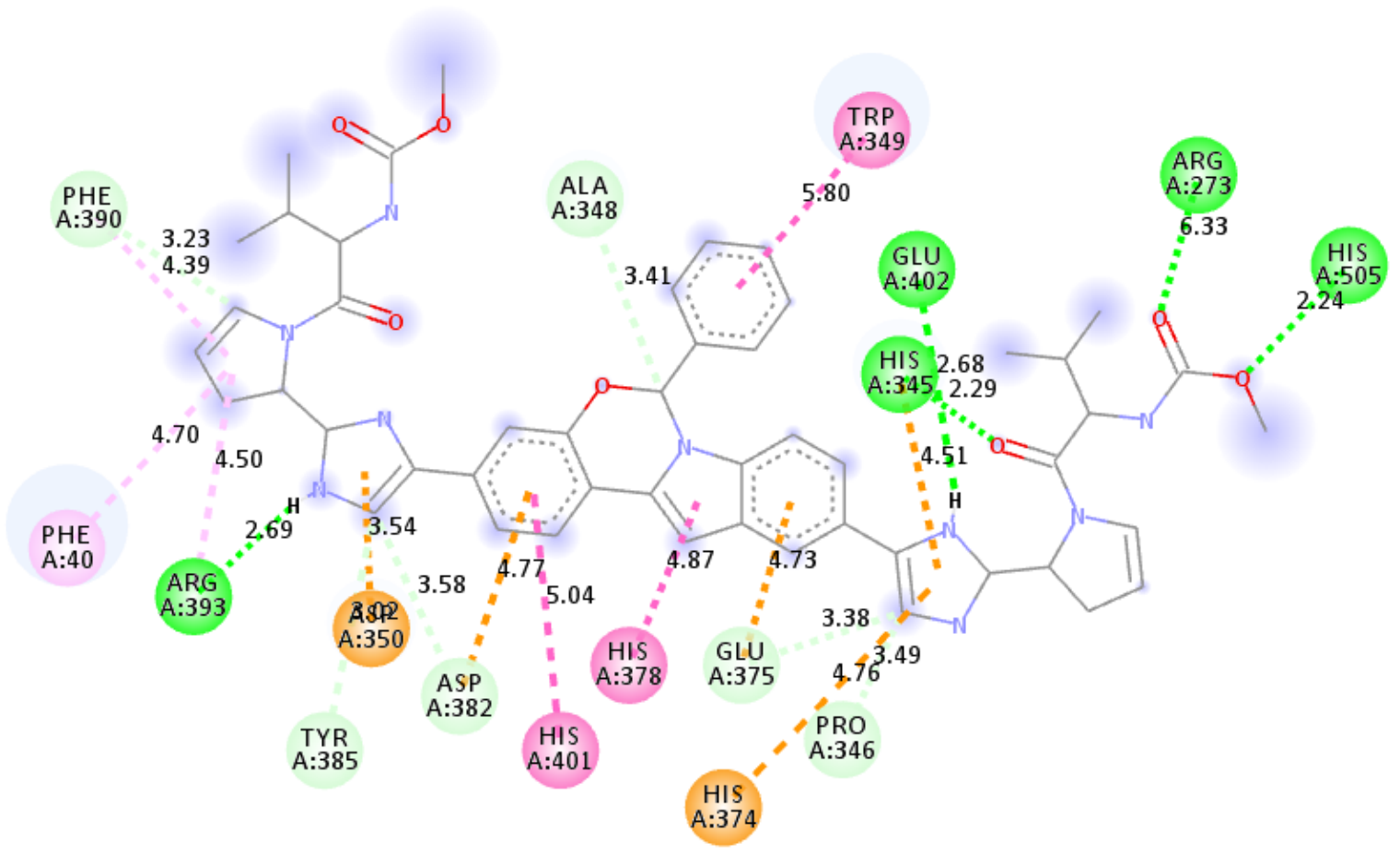

\section{Interactions}

Conventional Hydrogen Bond

Carbon Hydrogen Bond

Pi-Cation

Pi-Anion
Pi-Pi Stacked

Pi-Pi T-shaped

Alkyl

Pi-Alkyl

Figure 4 (expanded version). Docking interactions of elbasvir 8 (Tables 1 \& 2) with 6M0J. 


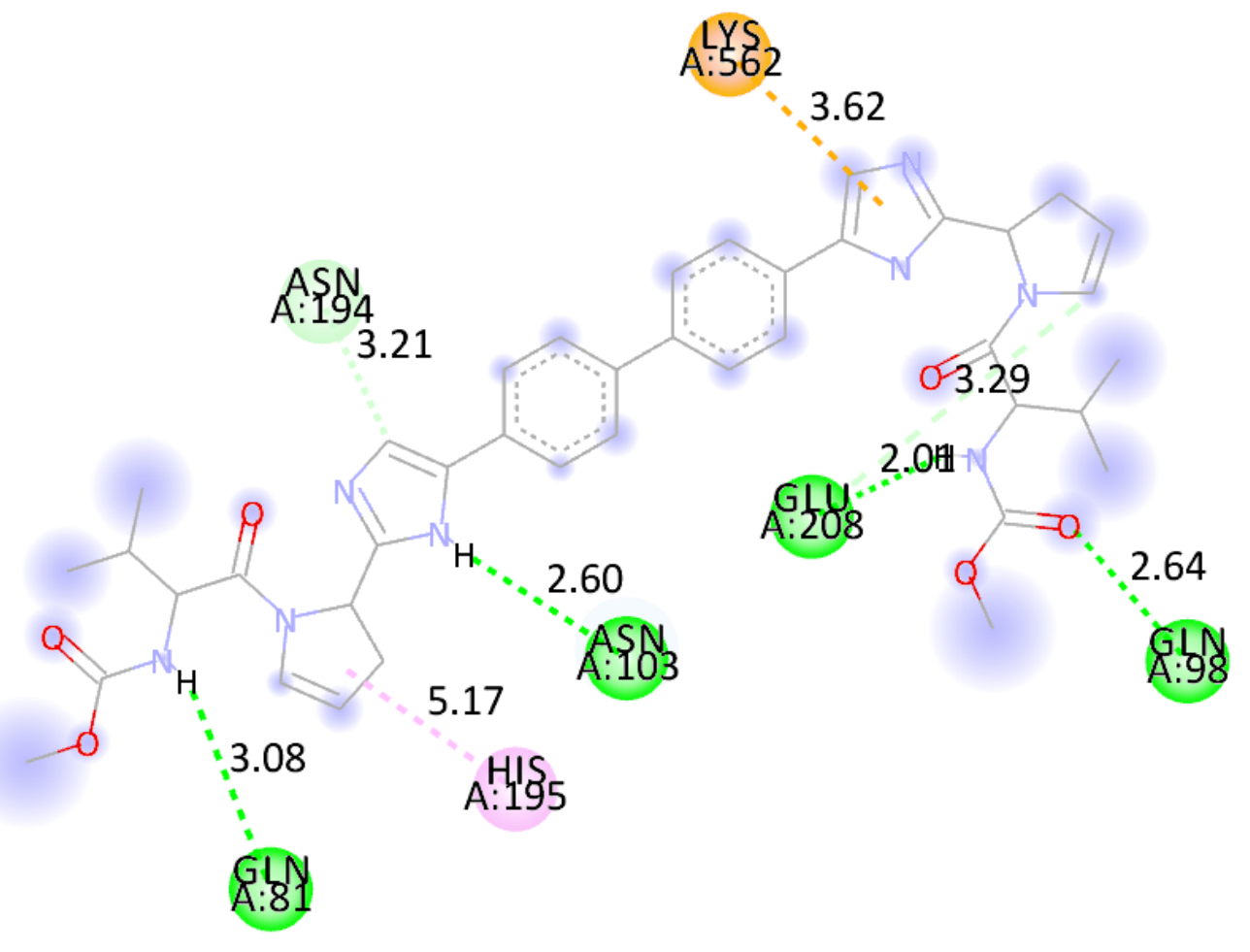

Interactions

Conventional Hydrogen Bond

Pi-Cation

Carbon Hydrogen Bond

Pi-Alkyl

Figure 5 (expanded version). Docking interactions of daclatasvir 2 (Tables 1 \& 2) with 6M0J. 


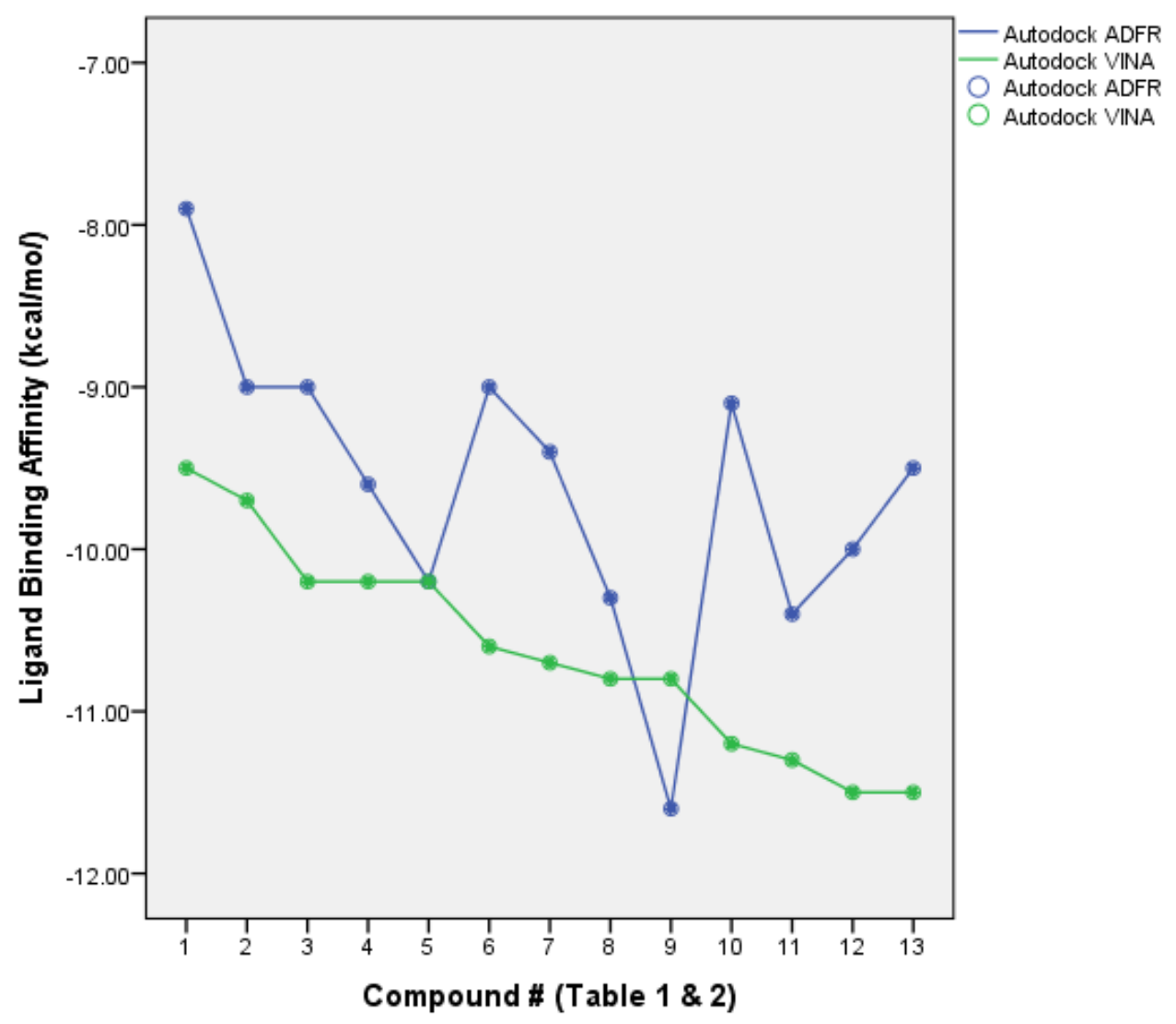

Graph 1A. Plot of ligand binding affinity (Table 2) for the protein 6M0J vs. Ligand \# (Table 2) using Autodock VINA (green points) and Autodock ADFR (blue points). The VINA values are lower except for ligand \#9. The trend observed is similar except for \#6, \#7, \#10-\#13. 
TABLE A1: SARS-CoV-2 Spike protein (6M0J) - ligand (compound in Table 2) docking interactions and corresponding binding scores (kcal.mol-1).

\begin{tabular}{|c|c|c|c|c|c|c|c|c|c|}
\hline$\#$ & Compound & $\begin{array}{c}\text { Docking Score } \\
\left(\text { kcal.mol }^{-1}\right)\end{array}$ & Distance (Å) & Category & Types & From & From Chemistry & To & To Chemistry \\
\hline \multirow[t]{17}{*}{1} & CID 132111205 & -9.5 & 3.02909 & H-Bond & Conventional H-Bond & A:MOLO:H & H-Donor & A:MOLO:O & H-Acceptor \\
\hline & & & 1.80563 & H-Bond & Conventional H-Bond & A:MOLO:H & H-Donor & $\begin{array}{c}\text { A:GLU402:O } \\
\text { E1 }\end{array}$ & H-Acceptor \\
\hline & & & 2.25809 & H-Bond & Conventional $\mathrm{H}-\mathrm{B}$ ond & $\begin{array}{c}\text { A:ARG273:HH } \\
12\end{array}$ & H-Donor & A:MOLO:O & H-Acceptor \\
\hline & & & 2.33213 & H-Bond & Conventional $\mathrm{H}$-Bond & $\begin{array}{c}\text { A:ARG273:HH } \\
22\end{array}$ & H-Donor & A:MOLO:O & H-Acceptor \\
\hline & & & 2.43307 & H-Bond & Conventional $\mathrm{H}-\mathrm{Bond}$ & $\begin{array}{c}\text { A:ASN394:HD } \\
21\end{array}$ & H-Donor & A:MOLO:O & H-Acceptor \\
\hline & & & 3.1139 & H-Bond & Carbon H-Bond & A:MOLO:C & H-Donor & A:PRO346:O & H-Acceptor \\
\hline & & & 3.31207 & H-Bond & Carbon H-Bond & A:MOLO:C & H-Donor & $\begin{array}{c}\text { A:GLU402:O } \\
\text { E2 }\end{array}$ & H-Acceptor \\
\hline & & & 3.61428 & H-Bond & Carbon H-Bond & A:MOLO:C & H-Donor & A:LEU391:O & H-Acceptor \\
\hline & & & 3.49244 & H-Bond & Carbon H-Bond & A:ARG393:CD & H-Donor & A:MOLO:F & H-Acceptor \\
\hline & & & 3.36522 & Halogen & Halogen (Fluorine) & A:PHE390:O & Halogen Acceptor & A:MOLO:F & Halogen \\
\hline & & & 4.04411 & Electrostatic & Pi-Cation & A:HIS378:NE2 & Positive & A:MOLO & Pi-Orbitals \\
\hline & & & 4.53041 & Electrostatic & Pi-Anion & $\begin{array}{c}\text { A:ASP350:OD } \\
2\end{array}$ & Negative & A:MOLO & Pi-Orbitals \\
\hline & & & 3.60422 & Electrostatic & Pi-Anion & $\begin{array}{c}A: G L U 375: O E \\
2\end{array}$ & Negative & A:MOLO & Pi-Orbitals \\
\hline & & & 3.81096 & Hydrophobic & Pi-Sigma & A:ASP350:CB & $\mathrm{C}-\mathrm{H}$ & A:MOLO & Pi-Orbitals \\
\hline & & & 5.73999 & Hydrophobic & Pi-Pi T-shaped & A:HIS401 & Pi-Orbitals & A:MOLO & Pi-Orbitals \\
\hline & & & 5.23505 & Hydrophobic & Pi-Alkyl & A:MOLO & Pi-Orbitals & A:ALA348 & Alkyl \\
\hline & & & 5.06486 & Hydrophobic & Pi-Alkyl & A:PHE390 & Pi-Orbitals & A:MOLO:C & Alkyl \\
\hline \multirow[t]{9}{*}{2} & daclatasvir & -9.7 & 2.01308 & H-Bond & Conventional $\mathrm{H}$-Bond & A:MOLO:H & H-Donor & A:GLU208:O & H-Acceptor \\
\hline & & & 2.92355 & H-Bond & Conventional $\mathrm{H}$-Bond & A:MOLO:H & H-Donor & A:MOLO:O & H-Acceptor \\
\hline & & & 2.60489 & H-Bond & Conventional H-Bond & A:MOLO:H & H-Donor & $\begin{array}{c}\text { A:ASN103:O } \\
\text { D1 }\end{array}$ & H-Acceptor \\
\hline & & & 3.07765 & H-Bond & Conventional H-Bond & A:MOLO:H & H-Donor & A:GLN81:O & H-Acceptor \\
\hline & & & 2.64492 & H-Bond & Conventional H-Bond & $\begin{array}{c}\text { A:GLN98:HE2 } \\
1\end{array}$ & H-Donor & A:MOLO:O & H-Acceptor \\
\hline & & & 3.28896 & H-Bond & Carbon H-Bond & A:MOLO:C & H-Donor & A:GLU208:O & H-Acceptor \\
\hline & & & 3.20594 & H-Bond & Carbon H-Bond & A:MOLO:C & H-Donor & A:ASN194:O & H-Acceptor \\
\hline & & & 3.50428 & H-Bond & Carbon H-Bond & A:MOLO:C & H-Donor & A:MOLO:O & H-Acceptor \\
\hline & & & 3.62415 & Electrostatic & Pi-Cation & A:LYS562:NZ & Positive & A:MOLO & Pi-Orbitals \\
\hline
\end{tabular}




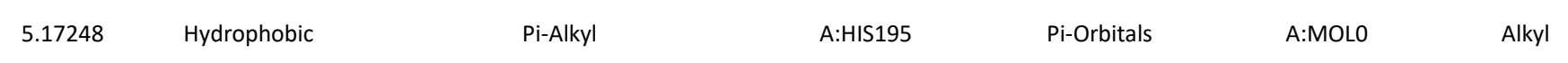

\begin{tabular}{|c|c|c|c|c|c|c|c|c|c|}
\hline$\#$ & Compound & Docking Score & Distance & Category & Types & From & From Chemistry & To & To Chemistry \\
\hline \multirow[t]{12}{*}{3} & CID 135195163 & -10.2 & 2.76768 & H-Bond & Conventional H-Bond & $\mathrm{A}: \mathrm{MOLO}: \mathrm{H}$ & H-Donor & A:GLN102:0 & H-Acceptor \\
\hline & & & 3.67039 & H-Bond & Carbon H-Bond & A:MOLO:C & H-Donor & A:ALA348:0 & H-Acceptor \\
\hline & & & 3.37242 & H-Bond & Carbon H-Bond & A:MOLO:C & H-Donor & $\begin{array}{c}\text { A:ASP382:O } \\
\text { D1 }\end{array}$ & H-Acceptor \\
\hline & & & 3.95872 & Hydrophobic & Pi-Sigma & A:MOLO:C & $\mathrm{C}-\mathrm{H}$ & A:HIS378 & Pi-Orbitals \\
\hline & & & 3.99209 & Hydrophobic & Pi-Sigma & A:MOLO:C & $\mathrm{C}-\mathrm{H}$ & A:HIS401 & Pi-Orbitals \\
\hline & & & 3.7675 & Hydrophobic & Pi-Sigma & A:LEU73:CD1 & $\mathrm{C}-\mathrm{H}$ & A:MOLO & Pi-Orbitals \\
\hline & & & 4.69305 & Hydrophobic & Pi-Pi Stacked & A:MOLO & Pi-Orbitals & A:PHE40 & Pi-Orbitals \\
\hline & & & 5.39312 & Hydrophobic & Alkyl & A:LYS74 & Alkyl & A:MOLO & Alkyl \\
\hline & & & 4.92266 & Hydrophobic & Pi-Alkyl & A:MOLO & Pi-Orbitals & A:LEU73 & Alkyl \\
\hline & & & 4.31193 & Hydrophobic & Pi-Alkyl & A:MOLO & Pi-Orbitals & A:LEU73 & Alkyl \\
\hline & & & 4.95388 & Hydrophobic & Pi-Alkyl & A:TRP349 & Pi-Orbitals & A:MOLO:C & Alkyl \\
\hline & & & 4.511 & Hydrophobic & Pi-Alkyl & A:TRP349 & Pi-Orbitals & A:MOLO:C & Alkyl \\
\hline \multirow[t]{13}{*}{4} & setrobuvir & -10.2 & 5.59025 & Electrostatic & Attractive Charge & A:MOLO:S & Positive & $\begin{array}{c}\text { A:ASP206:O } \\
\text { D1 }\end{array}$ & Negative \\
\hline & & & 2.99879 & H-Bond & Conventional $\mathrm{H}$-Bond & A:MOLO:H & H-Donor & $\begin{array}{c}\text { A:ASP206:O } \\
\text { D1 }\end{array}$ & H-Acceptor \\
\hline & & & 3.2193 & H-Bond & Conventional H-Bond & A:MOLO:O & H-Donor & $\begin{array}{c}\text { A:TYR202:O } \\
\mathrm{H}\end{array}$ & H-Acceptor \\
\hline & & & 2.791 & H-Bond & Conventional $\mathrm{H}$-Bond & $\begin{array}{c}\text { A:GLN102:HE } \\
22\end{array}$ & H-Donor & A:MOLO:O & H-Acceptor \\
\hline & & & 1.79612 & H-Bond & Conventional $\mathrm{H}$-Bond & A:SER511:HN & H-Donor & A:MOLO:O & H-Acceptor \\
\hline & & & 2.5854 & H-Bond & Conventional $\mathrm{H}$-Bond & $\begin{array}{c}\text { A:ARG514:HH } \\
22\end{array}$ & H-Donor & A:MOLO:O & H-Acceptor \\
\hline & & & 3.15561 & H-Bond & Carbon H-Bond & A:ASP206:CA & H-Donor & A:MOLO:O & H-Acceptor \\
\hline & & & 2.91982 & Halogen & Halogen (Fluorine) & A:LEU95:0 & Halogen Acceptor & A:MOLO:F & Halogen \\
\hline & & & 3.43208 & Electrostatic & Pi-Cation & A:LYS562:NZ & Positive & A:MOLO & Pi-Orbitals \\
\hline & & & 3.90131 & Hydrophobic & Pi-Sigma & A:LEU95:CD2 & $\mathrm{C}-\mathrm{H}$ & A:MOLO & Pi-Orbitals \\
\hline & & & 5.65454 & Other & Pi-Sulfur & A:MOLO:S & Sulfur & A:TYR510 & Pi-Orbitals \\
\hline & & & 5.64088 & Hydrophobic & Pi-Pi Stacked & A:TRP203 & Pi-Orbitals & A:MOLO & Pi-Orbitals \\
\hline & & & 5.07413 & Hydrophobic & Pi-Alkyl & A:MOLO & Pi-Orbitals & A:ALA99 & Alkyl \\
\hline \multirow[t]{5}{*}{5} & paritaprevir & -10.2 & 2.75011 & H-Bond & Conventional H-Bond & A:HIS345:HE2 & H-Donor & A:MOLO:O & H-Acceptor \\
\hline & & & 2.40033 & H-Bond & Conventional $\mathrm{H}$-Bond & A:HIS374:HE2 & H-Donor & A:MOLO:O & H-Acceptor \\
\hline & & & 2.46105 & H-Bond & Conventional $\mathrm{H}$-Bond & $\begin{array}{c}\text { A:ARG514:HH } \\
21\end{array}$ & H-Donor & A:MOLO:O & H-Acceptor \\
\hline & & & 3.19986 & H-Bond & Carbon H-Bond & A:MOLO:C & H-Donor & A:PRO346:0 & H-Acceptor \\
\hline & & & 3.35514 & H-Bond & Carbon H-Bond & A:MOLO:C & H-Donor & $\begin{array}{c}\text { A:GLU375:O } \\
\text { E2 }\end{array}$ & H-Acceptor \\
\hline
\end{tabular}




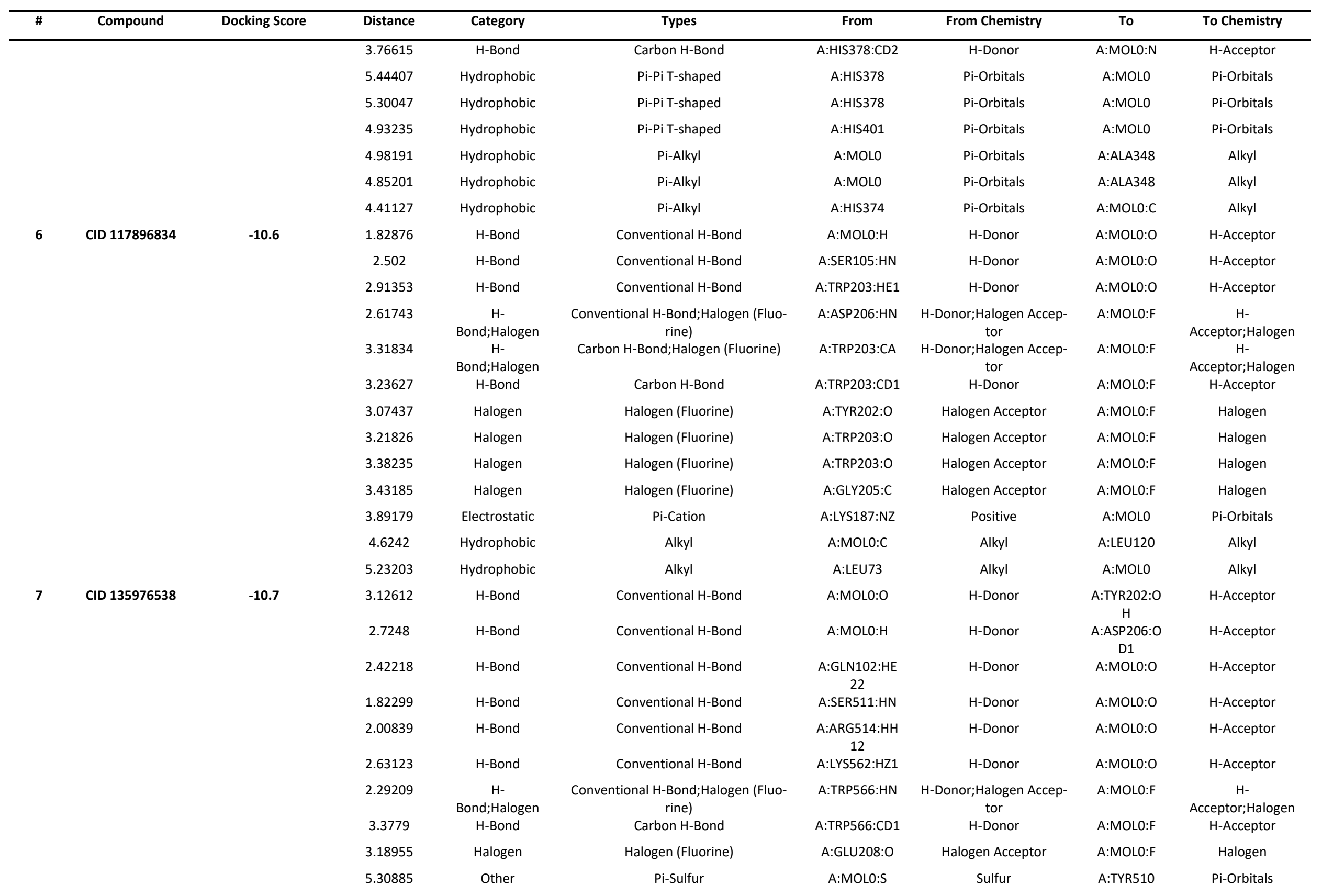




\begin{tabular}{|c|c|c|c|c|c|c|c|c|c|}
\hline$\#$ & Compound & Docking Score & Distance & Category & Types & From & From Chemistry & To & To Chemistry \\
\hline \multirow[t]{26}{*}{8} & elbasvir & -10.8 & 2.68147 & $\begin{array}{l}\text { Hydrogen } \\
\text { Bond }\end{array}$ & Conventional Hydrogen Bond & A:MOLO:H & H-Donor & $\begin{array}{c}\text { A:GLU402:0 } \\
\text { E1 }\end{array}$ & H-Acceptor \\
\hline & & & 2.69473 & $\begin{array}{l}\text { Hydrogen } \\
\text { Bond }\end{array}$ & Conventional Hydrogen Bond & A:MOLO:HN & H-Donor & A:ARG393:O & H-Acceptor \\
\hline & & & 3.0459 & $\begin{array}{l}\text { Hydrogen } \\
\text { Bond }\end{array}$ & Conventional Hydrogen Bond & A:MOLO:H & H-Donor & A:MOLO:O & H-Acceptor \\
\hline & & & 2.30849 & $\begin{array}{l}\text { Hydrogen } \\
\text { Bond }\end{array}$ & Conventional Hydrogen Bond & $\begin{array}{c}\text { A:ARG273:HH } \\
12\end{array}$ & H-Donor & A:MOLO:O & H-Acceptor \\
\hline & & & 2.09794 & $\begin{array}{l}\text { Hydrogen } \\
\text { Bond }\end{array}$ & Conventional Hydrogen Bond & $\begin{array}{c}\text { A:ARG273:HH } \\
22\end{array}$ & H-Donor & A:MOLO:O & H-Acceptor \\
\hline & & & 2.29188 & $\begin{array}{l}\text { Hydrogen } \\
\text { Bond }\end{array}$ & Conventional Hydrogen Bond & A:HIS345:HE2 & H-Donor & A:MOLO:O & H-Acceptor \\
\hline & & & 2.2444 & $\begin{array}{l}\text { Hydrogen } \\
\text { Bond }\end{array}$ & Conventional Hydrogen Bond & A:HIS505:HE2 & H-Donor & A:MOLO:O & H-Acceptor \\
\hline & & & 3.41364 & $\begin{array}{l}\text { Hydrogen } \\
\text { Bond }\end{array}$ & Carbon Hydrogen Bond & A:MOLO:C & H-Donor & A:ALA348:0 & H-Acceptor \\
\hline & & & 3.4857 & $\begin{array}{l}\text { Hydrogen } \\
\text { Bond }\end{array}$ & Carbon Hydrogen Bond & A:MOLO:C & H-Donor & A:PRO346:O & H-Acceptor \\
\hline & & & 3.37519 & $\begin{array}{l}\text { Hydrogen } \\
\text { Bond }\end{array}$ & Carbon Hydrogen Bond & A:MOLO:C & H-Donor & $\begin{array}{c}\text { A:GLU375:O } \\
\text { E2 }\end{array}$ & H-Acceptor \\
\hline & & & 3.58407 & $\begin{array}{l}\text { Hydrogen } \\
\text { Bond }\end{array}$ & Carbon Hydrogen Bond & A:MOLO:C & H-Donor & $\begin{array}{c}\text { A:ASP382:0 } \\
\text { D1 }\end{array}$ & H-Acceptor \\
\hline & & & 3.01616 & $\begin{array}{l}\text { Hydrogen } \\
\text { Bond }\end{array}$ & Carbon Hydrogen Bond & A:MOLO:C & H-Donor & $\begin{array}{c}\text { A:TYR385:O } \\
H\end{array}$ & H-Acceptor \\
\hline & & & 3.22657 & $\begin{array}{l}\text { Hydrogen } \\
\text { Bond }\end{array}$ & Carbon Hydrogen Bond & A:MOLO:C & H-Donor & A:PHE390:O & H-Acceptor \\
\hline & & & 4.50964 & Electrostatic & Pi-Cation & A:HIS345:NE2 & Positive & A:MOLO & Pi-Orbitals \\
\hline & & & 4.75507 & Electrostatic & Pi-Cation & A:HIS374:NE2 & Positive & A:MOLO & Pi-Orbitals \\
\hline & & & 3.54069 & Electrostatic & Pi-Anion & $\begin{array}{c}\text { A:ASP350:OD } \\
2\end{array}$ & Negative & A:MOLO & Pi-Orbitals \\
\hline & & & 4.72817 & Electrostatic & Pi-Anion & $\begin{array}{c}\text { A:GLU375:OE } \\
1\end{array}$ & Negative & A:MOLO & Pi-Orbitals \\
\hline & & & 4.768 & Electrostatic & Pi-Anion & $\begin{array}{c}\text { A:ASP382:OD } \\
2\end{array}$ & Negative & A:MOLO & Pi-Orbitals \\
\hline & & & 5.08862 & Hydrophobic & Pi-Pi Stacked & A:MOLO & Pi-Orbitals & A:HIS345 & Pi-Orbitals \\
\hline & & & 4.87127 & Hydrophobic & Pi-Pi T-shaped & A:MOLO & Pi-Orbitals & A:HIS378 & Pi-Orbitals \\
\hline & & & 5.98644 & Hydrophobic & Pi-Pi T-shaped & A:MOLO & Pi-Orbitals & A:TRP349 & Pi-Orbitals \\
\hline & & & 5.90652 & Hydrophobic & Pi-Pi T-shaped & A:TRP349 & Pi-Orbitals & A:MOLO & Pi-Orbitals \\
\hline & & & 5.0397 & Hydrophobic & Pi-Pi T-shaped & A:HIS401 & Pi-Orbitals & A:MOLO & Pi-Orbitals \\
\hline & & & 4.49695 & Hydrophobic & Alkyl & A:ARG393 & Alkyl & A:MOLO & Alkyl \\
\hline & & & 4.70205 & Hydrophobic & Pi-Alkyl & A:PHE40 & Pi-Orbitals & A:MOLO & Alkyl \\
\hline & & & 4.3899 & Hydrophobic & Pi-Alkyl & A:PHE390 & Pi-Orbitals & A:MOLO & Alkyl \\
\hline
\end{tabular}




\begin{tabular}{|c|c|c|c|c|c|c|c|c|c|}
\hline$\#$ & Compound & Docking Score & Distance & Category & Types & From & From Chemistry & To & To Chemistry \\
\hline \multirow[t]{10}{*}{9} & CID 122523225 & -10.8 & 2.06084 & H-Bond & Conventional H-Bond & A:MOLO:H & H-Donor & $\begin{array}{c}\text { A:TYR202:O } \\
H\end{array}$ & H-Acceptor \\
\hline & & & 3.15793 & H-Bond & Pi-Donor H-Bond & $\begin{array}{c}\text { A:GLN102:HE } \\
22\end{array}$ & H-Donor & A:MOLO & Pi-Orbitals \\
\hline & & & 3.77051 & Hydrophobic & Pi-Sigma & A:LEU95:CD2 & $\mathrm{C}-\mathrm{H}$ & A:MOLO & Pi-Orbitals \\
\hline & & & 3.8143 & Hydrophobic & Pi-Sigma & A:ASP206:CA & $\mathrm{C}-\mathrm{H}$ & A:MOLO & Pi-Orbitals \\
\hline & & & 4.88954 & Hydrophobic & Pi-Pi T-shaped & A:MOLO & Pi-Orbitals & A:TYR202 & Pi-Orbitals \\
\hline & & & 4.44512 & Hydrophobic & Alkyl & A:MOLO & Alkyl & A:LEU95 & Alkyl \\
\hline & & & 4.72196 & Hydrophobic & Alkyl & A:MOLO & Alkyl & A:VAL209 & Alkyl \\
\hline & & & 5.02012 & Hydrophobic & Alkyl & A:MOLO & Alkyl & A:VAL212 & Alkyl \\
\hline & & & 4.75014 & Hydrophobic & Alkyl & A:MOLO & Alkyl & A:PRO565 & Alkyl \\
\hline & & & 4.95251 & Hydrophobic & Pi-Alkyl & A:MOLO & Pi-Orbitals & A:VAL209 & Alkyl \\
\hline \multirow[t]{18}{*}{10} & CID 132182097 & -11.2 & 2.77734 & H-Bond & Conventional H-Bond & A:MOLO:H & H-Donor & A:ASP350:0 & H-Acceptor \\
\hline & & & 1.91491 & H-Bond & Conventional H-Bond & A:MOLO:H & H-Donor & A:ALA348:0 & H-Acceptor \\
\hline & & & 3.64415 & H-Bond & Carbon H-Bond & A:MOLO:C & H-Donor & A:ALA348:O & H-Acceptor \\
\hline & & & 3.6593 & H-Bond & Carbon H-Bond & A:MOLO:C & H-Donor & $\begin{array}{c}\text { A:ASP382:0 } \\
\text { D2 }\end{array}$ & H-Acceptor \\
\hline & & & 3.48743 & H-Bond & Carbon H-Bond & A:MOLO:C & H-Donor & A:ASN103:O & H-Acceptor \\
\hline & & & 3.68106 & Halogen & Halogen (Fluorine) & A:MOLO:C & Halogen Acceptor & A:MOLO:F & Halogen \\
\hline & & & 3.17743 & Halogen & Halogen (Fluorine) & A:MOLO:O & Halogen Acceptor & A:MOLO:F & Halogen \\
\hline & & & 3.90394 & Hydrophobic & Pi-Sigma & A:MOLO:C & $\mathrm{C}-\mathrm{H}$ & A:TRP349 & Pi-Orbitals \\
\hline & & & 3.9252 & Hydrophobic & Pi-Sigma & A:LEU73:CD2 & $\mathrm{C}-\mathrm{H}$ & A:MOLO & Pi-Orbitals \\
\hline & & & 5.10027 & Hydrophobic & Pi-Pi Stacked & A:MOLO & Pi-Orbitals & A:PHE40 & Pi-Orbitals \\
\hline & & & 4.19059 & Hydrophobic & Pi-Pi Stacked & A:MOLO & Pi-Orbitals & A:PHE40 & Pi-Orbitals \\
\hline & & & 5.14124 & Hydrophobic & Pi-Pi Stacked & A:MOLO & Pi-Orbitals & A:PHE40 & Pi-Orbitals \\
\hline & & & 5.96523 & Hydrophobic & Pi-Pi T-shaped & A:MOLO & Pi-Orbitals & A:TRP69 & Pi-Orbitals \\
\hline & & & 5.30272 & Hydrophobic & Alkyl & A:MOLO & Alkyl & A:LEU73 & Alkyl \\
\hline & & & 4.72841 & Hydrophobic & Alkyl & A:MOLO & Alkyl & A:LYS74 & Alkyl \\
\hline & & & 4.83096 & Hydrophobic & Pi-Alkyl & A:MOLO & Pi-Orbitals & A:LEU73 & Alkyl \\
\hline & & & 4.06623 & Hydrophobic & Pi-Alkyl & A:HIS378 & Pi-Orbitals & A:MOLO:C & Alkyl \\
\hline & & & 4.10686 & Hydrophobic & Pi-Alkyl & A:HIS401 & Pi-Orbitals & A:MOLO:C & Alkyl \\
\hline
\end{tabular}




\begin{tabular}{|c|c|c|c|c|c|c|c|c|c|}
\hline$\#$ & Compound & Docking Score & Distance & Category & Types & From & From Chemistry & To & To Chemistry \\
\hline \multirow[t]{10}{*}{11} & CID 131982844 & -11.3 & 2.05288 & H-Bond & Conventional $\mathrm{H}$-Bond & A:MOLO:H & H-Donor & $\begin{array}{l}\text { A:ASN394:O } \\
\text { D1 }\end{array}$ & H-Acceptor \\
\hline & & & 2.6574 & H-Bond & Conventional $\mathrm{H}$-Bond & A:MOLO:H & H-Donor & A:ALA348:0 & H-Acceptor \\
\hline & & & 2.39375 & H-Bond & Conventional $\mathrm{H}$-Bond & A:MOLO:H & H-Donor & $\begin{array}{l}\text { A:ASN394:O } \\
\text { D1 }\end{array}$ & H-Acceptor \\
\hline & & & 4.10406 & Hydrophobic & Pi-Pi Stacked & A:MOLO & Pi-Orbitals & A:PHE40 & Pi-Orbitals \\
\hline & & & 4.56059 & Hydrophobic & Pi-Pi Stacked & A:MOLO & Pi-Orbitals & A:PHE40 & Pi-Orbitals \\
\hline & & & 4.50396 & Hydrophobic & Pi-Pi Stacked & A:MOLO & Pi-Orbitals & A:PHE40 & Pi-Orbitals \\
\hline & & & 4.4529 & Hydrophobic & Pi-Pi Stacked & A:MOLO & Pi-Orbitals & A:TRP349 & Pi-Orbitals \\
\hline & & & 5.20923 & Hydrophobic & Pi-Pi Stacked & A:TRP349 & Pi-Orbitals & A:MOLO & Pi-Orbitals \\
\hline & & & 4.7727 & Hydrophobic & Pi-Alkyl & A:MOLO & Pi-Orbitals & A:ARG393 & Alkyl \\
\hline & & & 4.66894 & Hydrophobic & Pi-Alkyl & A:PHE40 & Pi-Orbitals & A:MOLO:C & Alkyl \\
\hline \multirow[t]{13}{*}{12} & CID 117860584 & -11.5 & 3.02799 & H-Bond & Conventional H-Bond & A:TRP69:HE1 & H-Donor & A:MOLO:O & H-Acceptor \\
\hline & & & 2.5555 & H-Bond & Conventional H-Bond & A:TRP69:HE1 & H-Donor & A:MOLO:O & H-Acceptor \\
\hline & & & 2.25165 & $\begin{array}{c}\mathrm{H}- \\
\text { Bond;Halogen }\end{array}$ & $\begin{array}{l}\text { Conventional H-Bond; Halogen (Fluo- } \\
\text { rine) }\end{array}$ & $\begin{array}{c}\text { A:ARG393:HH } \\
11\end{array}$ & $\begin{array}{c}\text { H-Donor; Halogen Accep- } \\
\text { tor }\end{array}$ & A:MOLO:F & $\begin{array}{c}\mathrm{H}- \\
\text { Acceptor; Halogen }\end{array}$ \\
\hline & & & 3.5739 & H-Bond & Carbon H-Bond & A:MOLO:C & H-Donor & $\begin{array}{l}\text { A:GLU375:O } \\
\text { E1 }\end{array}$ & H-Acceptor \\
\hline & & & 2.94114 & H-Bond & Carbon H-Bond & A:ARG393:CD & H-Donor & A:MOLO:F & H-Acceptor \\
\hline & & & 5.20044 & Other & Pi-Sulfur & A:MOLO:S & Sulfur & A:TRP69 & Pi-Orbitals \\
\hline & & & 5.5714 & Hydrophobic & Pi-Pi Stacked & A:MOLO & Pi-Orbitals & A:PHE390 & Pi-Orbitals \\
\hline & & & 5.04414 & Hydrophobic & Pi-Pi Stacked & A:MOLO & Pi-Orbitals & A:PHE390 & Pi-Orbitals \\
\hline & & & 5.13854 & Hydrophobic & Pi-Pi Stacked & A:MOLO & Pi-Orbitals & A:PHE390 & Pi-Orbitals \\
\hline & & & 5.09894 & Hydrophobic & Pi-Alkyl & A:MOLO & Pi-Orbitals & A:ARG393 & Alkyl \\
\hline & & & 5.38386 & Hydrophobic & Pi-Alkyl & A:PHE40 & Pi-Orbitals & A:MOLO & Alkyl \\
\hline & & & 4.76343 & Hydrophobic & Pi-Alkyl & A:TRP349 & Pi-Orbitals & A:MOLO & Alkyl \\
\hline & & & 4.46894 & Hydrophobic & Pi-Alkyl & A:HIS378 & Pi-Orbitals & A:MOLO:C & Alkyl \\
\hline \multirow[t]{7}{*}{13} & CID 132247343 & -11.5 & 3.0494 & H-Bond & Conventional $\mathrm{H}$-Bond & A:MOLO:H & H-Donor & A:MOLO:O & H-Acceptor \\
\hline & & & 2.32349 & H-Bond & Conventional H-Bond & A:SER47:HG & H-Donor & A:MOLO:N & H-Acceptor \\
\hline & & & 2.02275 & H-Bond & Conventional $\mathrm{H}$-Bond & $\begin{array}{c}\text { A:ARG514:HH } \\
21\end{array}$ & H-Donor & A:MOLO:O & H-Acceptor \\
\hline & & & 2.81488 & H-Bond & Conventional $\mathrm{H}$-Bond & $\begin{array}{c}\text { A:ARG514:HH } \\
22\end{array}$ & H-Donor & A:MOLO:O & H-Acceptor \\
\hline & & & 3.03934 & H-Bond & Pi-Donor H-Bond & A:SER47:HG & H-Donor & A:MOLO & Pi-Orbitals \\
\hline & & & 5.40007 & Hydrophobic & Pi-Pi Stacked & A:MOLO & Pi-Orbitals & A:PHE390 & Pi-Orbitals \\
\hline & & & 4.73935 & Hydrophobic & Pi-Pi Stacked & A:MOLO & Pi-Orbitals & A:PHE390 & Pi-Orbitals \\
\hline
\end{tabular}




\begin{tabular}{|c|c|c|c|c|c|c|c|c|c|}
\hline$\#$ & Compound & Docking Score & Distance & Category & Types & From & From Chemistry & To & To Chemistry \\
\hline & & & 5.44719 & Hydrophobic & Pi-Pi Stacked & $\mathrm{A}: \mathrm{MOLO}$ & Pi-Orbitals & A:TRP349 & Pi-Orbitals \\
\hline & & & 5.27463 & Hydrophobic & Alkyl & A:MOLO:C & Alkyl & A:MET62 & Alkyl \\
\hline
\end{tabular}

TABLE A2: Physicochemical and ADMET properties of potential drug candidates $\underline{10}-\underline{13}$ (Table 2)

\begin{tabular}{|c|c|c|c|c|c|c|c|c|c|c|c|}
\hline PubChem ID & Comp. ID \# Table 2 & $\mathrm{MW}<500$ & $H A<10$ & $\mathrm{HD}<5$ & $\log P<5$ & TPSA $\leq 140$ & CaCO-2 $(\mathrm{cm} / \mathrm{s})$ & $\log S>-5$ & BBB & HIA & admetSAR result \\
\hline CID 132247343 & 13 & 767.9 & 10 & 3 & 3.5 & 198 & 0.8615 & -3.689 & + & + & within ref. range \\
\hline CID 117860584 & 12 & 789.8 & 10 & 3 & 3.1 & 190 & 0.8544 & -3.765 & + & + & within ref. range \\
\hline CID 131982844 & 11 & 767.9 & 10 & 3 & 3.5 & 198 & 0.8471 & -3.740 & + & + & within ref. range \\
\hline CID 132182097 & 10 & 713.8 & 8 & 4 & 4.2 & 147 & 0.8404 & -3.692 & + & + & within ref. range \\
\hline
\end{tabular}

